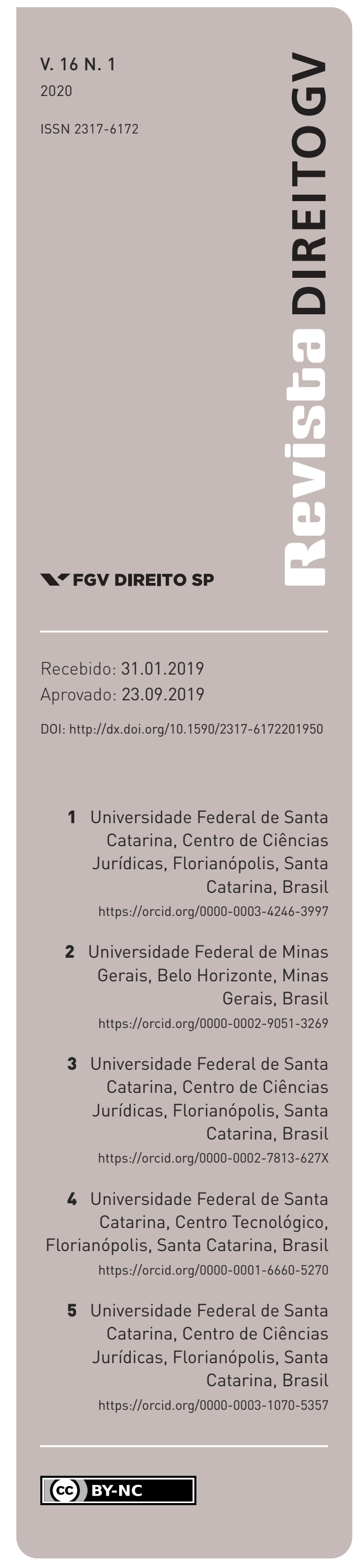

\section{Entraves ao governo aberto na Justiça Federal brasileira}

\author{
HINDRANCES TO OPEN GOVERNMENT IN BRAZILIAN FEDERAL JUSTICE \\ Isabela Cristina Sabo ${ }^{1}$, Lahis Pasquali Kurtz², Paula Adão \\ Reginaldo ${ }^{3}$, Paloma Maria Santos ${ }^{4}$ Aires José Rover
}

\section{Resumo}

Com a promessa de dar mais agilidade e transparência aos trâmites processuais, o Poder Judiciário, no contexto de governo aberto e acesso à Justiça, vem implementando, ao longo da última década, o processo judicial eletrônico para aprimorar o desenvolvimento de suas atividades administrativas. Tendo em vista analisar até que ponto isso se efetiva na prática, buscou-se verificar, por meio de um estudo de caso estruturado no âmbito da Justiça Federal brasileira, os entraves ao acesso de dados e a disponibilização de informações processuais. Tal verificação considerou: a agilidade no retorno das solicitações; a diversidade de órgãos internos acionados; o grau de informatização dos processos judiciais eletrônicos; a transparência no retorno das solicitações; e a burocracia envolvida no manejo das solicitações. As dificuldades no acesso aos dados processuais, à aplicação da Lei de Acesso à Informação, bem como a lenta e desordenada informatização demonstram que ainda há uma distância considerável entre a realidade forense e os avanços legislativos.

\section{Palavras-chave}

Governo aberto; acesso à Justiça; Lei de Acesso à Informação; processo judicial eletrônico; Justiça Federal brasileira.

\section{Abstract}

Promising more agility and transparency to lawsuit procedures, Judicial Branch, in a context of open government and access to justice, through the last decade, has been implementing electronic case filing to enhance its management activities. Aiming to analyze to what extent this is effective in practice, we sought to verify, by means of a case study on Brazilian Federal Justice scope, the hindrances to obtain access to judicial process data and information. This analysis considered: agility in returning solicitations; diversity of internal organs requested; degree of informatization of electronic case filing; transparency in returning requests; and bureaucracy involved on handling requests. The difficulties in accessing data of judicial files, to the application of Access to Information Act, as well as the slow and chaotic informatization show that there is still considerable distance between courts reality and regulation advances.

\section{Keywords}

Open government; access to justice; Access to Information Act; electronic case filing; Brazilian Federal Justice. 


\section{INTRODUÇÃO}

No contexto de governo aberto, acesso à informação e acesso à Justiça, fala-se do processo judicial eletrônico como ferramenta que proporciona maior agilidade, confiabilidade e publicidade aos atos processuais. Para além de ser uma forma de acesso remoto às atividades processuais, dispensando o deslocamento e a total intermediação pelo Poder Judiciário e por advogados entre as partes e demais atores envolvidos na tutela judicial, o processo judicial eletrônico é uma ferramenta que gerencia dados e informações. Por meio dele, pode-se ter acesso à organização e à produção de dados e informações sobre o desempenho do Poder Judiciário, bem como dos processos dos quais o Estado faz parte.

Em teoria, a informatização processual possibilita a identificação de gargalos na atividade judiciária, além da criação de novas soluções automatizadas e padronizadas para lidar com atividades de gerenciamento processual. Ao mesmo tempo que daria opções mais acuradas e previsíveis ao gestor judicial em busca de celeridade nos trâmites, forneceria a possibilidade de fiscalização informada ao cidadão, ao publicizar o desenrolar dos processos de maneira efetiva.

O que se questiona, nesse cenário, é se a realidade reflete essas promessas da informatização e do governo aberto, ou o quanto ela deixa claro quais são os problemas visualizados pela teoria - como em Janssen, Charalabidis e Zuiderwijk (2012, p. 261), os quais identificam mitos sobre esse modelo -, mas talvez não pelos idealizadores do processo eletrônico no Brasil. Não é de maneira automática que se dá a dinamização e o uso de dados para gerar soluções efetivas e eficientes aos problemas enfrentados nas instituições. Na prática, o acesso a dados e informações extraídos do sistema de publicização de trâmites do processo judicial eletrônico pode apresentar problemas, revelando barreiras ao acesso prometido pela informatização. Mitos - como os de que disponibilizar informação on-line é suficiente, de que abrir dados significa abertura do governo, de que, quanto mais dados disponíveis, melhor será o grau de aproximação e compreensão do cidadão sobre aquelas atividades - são revelados.

Diante dessa conjuntura, busca-se, pelo método indutivo e por meio de um estudo de caso, investigar quais entraves o cidadão encontra ao buscar acesso a dados e informações processuais na Justiça Federal brasileira. A escolha da Justiça Federal e dos procedimentos de execução fiscal promovidos pela União se deu em função da intenção de comparar, utilizando os mesmos critérios, trâmites semelhantes nos diferentes tribunais com amplitude nacional.

A finalidade desta coleta é acessar os dados e as informações processuais a fim de, em etapa posterior da pesquisa, verificar a atuação do Poder Público (Poder Judiciário) no sentido de melhor gerenciar suas atividades-fim, sugerir quais funcionalidades e ferramentas no processo judicial eletrônico poderiam ser implementadas em maior escala em outros tribunais. Para o cidadão leigo, essa informação permitiria fiscalizar a atuação processual no sentido de um acesso à Justiça que dê conta das demandas apresentadas.

O trabalho divide-se em três partes, além desta introdução: a primeira parte, contextual, que trata da conexão entre processo judicial eletrônico e governo aberto, em especial no 
contexto de um Judiciário que busca cumprir com preceitos de acesso à Justiça; a segunda, que faz uma análise crítica da realidade do acesso a dados e informações processuais a partir de metadados obtidos pela equipe de pesquisa em tentativas junto à Justiça Federal; e a terceira, na qual se apresentam as conclusões e a resposta ao problema de pesquisa lançado.

\section{i Contexto e Revisão bibliográficA: gOVerno ABerto no PODER JUdiciário} BRASILEIRO

Nesta seção, a fim de dar aporte à parte analítica do artigo, conceitua-se "governo aberto", destacando o papel de dados abertos em sua concretização, bem como se apresentam as premissas do processo judicial eletrônico para esse novo modelo de governo que é possibilitado pelo avanço das tecnologias digitais.

\section{I GOVERNO ABERTO E LEI DE ACESSO À INFORMAÇÃO}

Não há na literatura um consenso sobre o que se entende por "governo aberto". Em que pese os distintos conceitos encontrados, por vezes confundidos com os de "governo eletrônico" ou "governança eletrônica", diversas instâncias do Estado têm implementado iniciativas de governo aber to como forma de ampliar a transparência e a accountability, a fim de combater a corrupção e fomentar o desenvolvimento econômico (RUVALCABA-GOMEZ, CRIADO e GIL-GARCIA, 2018, p. 1).

Segundo Calderón e Lorenzo (2010, p. 215), a ideia de governo aberto é tão velha quanto a própria democracia e está implícita na maioria das leis fundamentais e constituições dos Estados ocidentais modernos. Trata-se da evolução para um governo cujas ações, projetos e programas visem à promoção da transparência, à prestação de contas e à responsabilização dos agentes públicos (accountability), ao incentivo à participação social nos debates e na proposição de soluções que busquem um governo mais responsivo e eficiente, e ao desenvolvimento e utilização de novas tecnologias na gestão e na prestação de serviços públicos que atendam às necessidades dos cidadãos (BRASIL, s.d.).

Sua materialização implica uma transformação profunda sobre o modo como se dá a interação sociopolítica entre os diferentes atores, o que requer um modelo de democracia mais agregativo, que dê prioridade à representatividade e aos processos e cuja orientação seja voltada a criar um governo mais transparente, acessível e receptivo, passível de escrutínio e supervisão cidadã (CRUZ-RUBIO, 2015, p. 139).

Quando se fala de Governo Aberto, não está se falando somente da ideia de governança, nem se fala somente em renovar a administração pública, estamos falando de reinventar e reorganizar todo o nosso sistema, dando-lhe novas capacidades em todos os seus pontos, provenientes da abertura à cidadania (CALDERÓN e LORENZO, 2010, p. 16). 
A abertura do governo está diretamente ligada ao direito de acesso à informação. Sua posse amplia o potencial do cidadão para fiscalizar as ações empreendidas pelo governo, criar novos serviços e melhorar substancialmente a vida em sociedade.

Além desses benefícios no campo da transparência e do controle social, a adoção do governo aberto introduz formas inovadoras de governança colaborativa, na medida em que possibilita a criação de informações e aplicativos pela própria sociedade, atuando de maneira participativa e colaborativa com o governo e as instituições privadas (VAZ, RIBEIRO e MATHEUS, 2010, p. 48; MAIER-RABLER e HUBER, 2011, p. 184).

Assim, um governo mais aberto pode reforçar a legitimidade e a credibilidade da instituição e ajudar a responder às crescentes demandas públicas por informações e serviços mais acessíveis e de melhor qualidade. O grande desafio que os governos enfrentam no momento é conseguir equilibrar a necessidade de preservar a abertura dos dados com a de garantir a segurança nacional (OECD, 2005, p. 3).

A ideia de governo aberto, portanto, perpassa por práticas de dados abertos, que são uma das facetas desse modelo, aliadas à transparência e à participação ${ }^{1}$ - e esta última não será o enfoque do presente trabalho, visto que o aporte dos dados aqui apresentados não permite conclusões acerca desse aspecto do governo aberto no Poder Judiciário. Tal aspecto merece estudos complementares, não sendo adequado, metodologicamente, fazer inferências acerca da temática sem observar dados que as suportem, como assinalado por King, Keohane e Verba (1994, p. 119). O enfoque da discussão aqui traçada permeia, por isso, os aspectos relativos a dados abertos, tocando por vezes na temática da transparência.

Janssen, Charalabidis e Zuiderwijk (2012, p. 261) salientam que nem sempre é fácil encontrar, interpretar, processar e utilizar os dados disponibilizados pelo governo. Há que se lidar com o excesso de formalismos, os distintos formatos e as capacidades de análise do que é fornecido.

A questão é que nem sempre os dados estão, de fato, abertos. Um dado pode ser considerado aberto quando nenhuma instituição tenha sobre ele controle exclusivo, direito autoral ou patente, e quando for possível sua utilização e redistribuição independentemente da finalidade, estando, no máximo, sujeito à exigência de crédito da autoria e da preservação da licença aberta (IMPRENSA NACIONAL, s.d.).

Para Diniz (2010, p. 4), o objetivo da disponibilização de dados abertos governamentais é ultrapassar as barreiras impostas aos usuários de informações do serviço público, de modo que eles facilmente encontrem, acessem, entendam e utilizem os dados da maneira que melhor

1 Participação, neste artigo, é entendida no sentido de um modelo que caminhe para a democracia participativa, em que o exercício da cidadania vai além do voto e consiste em espaços de contato com o Poder Público, podendo influenciar e também concretamente participar da elaboração e da execução de políticas. Ver: PÉREZ LUÑO, Antonio-Enrique. ¿Ciberciudadani@o ciudadania.com. Barcelona: Editorial Gedisa, 2004, p. 67. 
lhes convier, abrindo a possibilidade para que possam misturá-los e combiná-los, agregando ainda mais valor.

Os dados abertos governamentais exercem um efeito positivo sobre as políticas públicas (BRASIL, 2019), uma vez que possibilitam:

: Inclusão: fornecer dados em formatos padronizados abertos e acessíveis permite que qualquer cidadão utilize qualquer ferramenta de software para adaptá-los a suas necessidades.

: Transparência: informações do setor público abertas e acessíveis melhoram a transparência, pois as partes interessadas podem usá-las da maneira mais adequada a seu propósito.

: Responsabilidade: os conjuntos apropriados de dados abertos, devidamente associados, podem oferecer vários pontos de vista sobre o desempenho dos governos no cumprimento de suas metas em políticas públicas.

Fora isso, algumas barreiras para a adoção dos dados abertos já começam a ficar evidentes: dados dispersos (espalhados), dificuldade de publicação dos dados em função de sua qualidade (conjunto de dados desconexos, sem metadados ou semântica), alto custo para sua administração e falta de clareza na forma de licenciamento (SALM JÚNIOR, 2012, p. 70-71).

No âmbito internacional, a Open Government Partnership (OGP) é uma iniciativa que objetiva assegurar compromissos concretos de governos em relação aos cidadãos, tendo em vista promover a transparência, o combate à corrupção, a participação social e o fomento ao desenvolvimento de novas tecnologias (COELHO e WAISBICH, 2013, p. 13).

O Brasil, como um dos oito membros fundadores e parceiro da OGP, participa dessa ação desde 2011 (COELHO e WAISBICH, 2013, p. 13). Na esfera dessas atividades, foi criado, no dia 15 de setembro de 2011, pela então Presidente da República Dilma Rousseff, por meio de decreto sem número, o qual institui o Plano de Ação Nacional sobre Governo Aberto (PNGA), o Comitê Interministerial para Governo Aberto (CIGA), coordenado pela Controladoria Geral da União (CGU).

Uma das principais medidas adotadas pelo governo para implementar o PNGA foi a promulgação da Lei de Acesso à Informação (LAI) em 18 de novembro de 2011 (BRASIL, 2011), cujo principal objetivo é consolidar os acordos firmados pelo Brasil de abertura das informações públicas. A referida lei, que representa um importante fortalecimento da democracia brasileira, caminha em consonância com os preceitos institucionais e com diversos tratados ${ }^{2}$ dos quais o Brasil é signatário.

2 O Brasil é signatário de diversos tratados internacionais que objetivam aumentar a transparência e combater a corrupção: Convenção Interamericana contra a Corrupção (OEA), Convenção contra a Corrupção de 
Ao estabelecer esse marco regulatório, com a promulgação da LAI, o Brasil dá um importante passo em direção à consolidação e ao amadurecimento do processo democrático, possibilitando a transição da cultura do segredo para a do acesso. Nesse cenário, a informação é a regra, e o sigilo, a exceção (SANTOS, BERNARDES e ROVER, 2012, p. 46-47).

Essa transformação, entretanto, não se dá sem que haja esforços concretos. Existem alguns mitos que tornam fácil uma visão demasiadamente otimista acerca da abertura de dados governamentais em qualquer grau, quando más práticas podem, inclusive, ter efeito reverso à ampliação democrática. Sobre tais mitos, Janssen, Charalabidis e Zwiderwijk (2012, p. 264-266) alertam que: (i) os benefícios da publicização de dados não são automáticos; (ii) existem restrições quanto aos custos e observância a direitos pessoais para isso ser realizado; (iii) não se trata de simplesmente disponibilizar dados, mas de torná-los amigáveis e utilizáveis pelo cidadão; (iv) as necessidades e capacidades dos cidadãos devem ser consideradas; e (v) informação sem direcionamento pode trazer confusão e incompreensão ao cidadão sobre as atividades públicas, resultando em um governo mais distante e fechado.

Esse panorama de mitos sobre dados abertos e governo aberto pode tornar uma implementação meramente formal ou parcial da LAI, ainda que bem-intencionada, potencialmente prejudicial ao contexto de cultura do acesso que ela visa promover. Ignorar as barreiras e os problemas causados por sua não superação pode gerar um afastamento ainda maior entre governo e cidadão. Gerar uma impressão de que a fronteira governamental é intransponível - reforçando a sensação de impotência do cidadão ante a estrutura institucional em que ele deveria sentir-se apto e capaz de influenciar - é um grande risco da má-implementação de um projeto de governo aberto.

Essa adoção despretensiosa de algumas medidas de dados abertos, como se fossem sinônimos de governo aberto, torna-se um perigo ainda maior quando se fala no Poder Judiciário. Nesse âmbito, a cultura do acesso não se dá somente por meio da ideia de acessar os dados, mas também por meio de inserção do cidadão no sistema, possibilitando-lhe exigir do Estado a tutela de seus direitos, concretizando o acesso à Justiça.

Saber como e onde ingressar com uma ação judicial, poder acompanhar a atuação dos tribunais e conhecer a interpretação dada ao aparato legislativo na tutela de fatos cotidianos é fundamental para a integração do cidadão como sujeito ativo nas políticas públicas. Como a própria possibilidade de demandar junto ao poder estatal e perceber sua atuação liga-se à capacidade de compreendê-lo e criticá-lo, o acesso à Justiça e o acesso à informação no Poder Judiciário se conectam profundamente, uma vez que esse poder é mais técnico e obscuro aos

Funcionários Públicos Estrangeiros em Transações Comerciais Internacionais da Organização para Cooperação e Desenvolvimento Econômico (OECD) e Convenção das Nações contra a Corrupção (ONU). 
leigos do que o Poder Executivo e o Poder Legislativo, cujas composição e atuação são representativas e flexíveis à pressão social (DAHL, 2012, p. 84; DALLARI, 2002, p. 6).

\section{I.2 O PROCESSO JUDICIAL ELETRÔNICO E O ACESSO À JUSTIÇA NO GOVERNO ABERTO}

A informatização processual e o acesso à Justiça são temas que vêm sendo tratados de maneira associada, conforme levantamento feito por Kurtz (2017, p. 103-105). Autores apontam a burocracia como algo negativo e defendem que o processo judicial eletrônico pode ser um importante instrumento contra a chamada crise do Poder Judiciário, a qual é causada por descrédito do cidadão ante a complexidade e a obscuridade da tramitação processual para o público leigo. Esse problema, segundo a literatura majoritária, poderia ser solucionado por procedimentos mais simples e econômicos, bem como pela facilidade de acessar o sistema (KURTZ, 2017, p. 107).

Uma das funções do processo judicial eletrônico é o auxílio no acesso a dados e informações processuais, ao tornar factível sua abertura ao público. No Brasil, o processo judicial eletrônico inseriu-se no campo legislativo, dentro do contexto da Reforma Judicial introduzida pela Emenda Constitucional n. 45, de 2004, pela promulgação da Lei n. 11.419, de 19 de dezembro de 2006. Seu escopo foi materializar a intenção de disciplinar o instituto, com a perspectiva de agilizar e dinamizar os trâmites processuais, encurtando os entraves causados pela burocracia e pelo distanciamento sempre comum no encaminhamento da causa (ABRÃO, 2017, p. 5).

Entre os pontos disciplinados pela lei, menciona-se a utilização do meio eletrônico indistintamente para todas as ramificações do processo (cível, penal, trabalhista, fazenda pública, etc.), a comunicação eletrônica dos atos processuais, destacando-se a criação do Diário da Justiça eletrônico, e os documentos eletrônicos, viabilizados pela certificação digital.

Ao regulamentar a comunicação eletrônica, o que a lei visa reduzir é a burocratização e a demora de tramitação no ambiente cartorário com a juntada de documentos e com as certificações manuais - o chamado "tempo morto" (OLIVEIRA, 2015, p. 393). Também se ganha em precisão, assegurando o registro da data e da hora de sua prática. Além disso, a partir do instante em que se cria o Diário da Justiça eletrônico, os sistemas informatizados dos tribunais deverão estar em perfeita consonância com as informações prestadas em seus portais eletrônicos, superando-se o entendimento de que esses canais têm caráter meramente consultivo. Se antes a prática de acompanhamento dos feitos via internet já lhes atribuía mais celeridade, com o advento da lei essa prática tornou-se oficializada, vinculando as informações constantes nos portais eletrônicos dos tribunais (ALMEIDA FILHO, 2007, p. 222, p. 230-231).

Outro ponto relevante é que a lei impõe aos órgãos do Poder Judiciário a utilização, de preferência, de programas com código aberto, acessíveis ininterruptamente por meio da rede de alcance mundial, priorizando-se sua padronização. Ressalta-se, ainda, a possibilidade de que os livros cartorários e demais repositórios dos órgãos do Poder Judiciário sejam gerados e armazenados em meio totalmente eletrônico. 
Desse modo, o conteúdo das informações processuais não estará, necessariamente, armazenado no local geográfico onde, antes, o processo se encontrava fisicamente. A justiça eletrônica estará ligada à rede computacional, sendo acessada em qualquer lugar do mundo, a qualquer momento, desde que disponível de modo remoto. As redes computacionais não exigem consultas presenciais, de maneira convencional (físico-espacial), o que faz que se rompa, pelo advento da lei e com a respectiva implantação do processo judicial eletrônico, o conceito legal espacial de divisão judiciária física centralizada dos feitos, possibilitando a atuação apenas por conexões remotas (ATHENIENSE, 2010, p. 97).

Esse ponto da legislação pode ser assimilado como o de maior interesse na proposta de governo aberto, uma vez que a intenção do legislador, ao dispor sobre o manejo das informações processuais pelo meio eletrônico, é torná-lo possível tanto aos servidores do Poder Judiciário como aos advogados, às partes e, sobretudo, a qualquer cidadão leigo.

O funcionamento de todas essas regras, porém, está associado à disponibilidade e ao interesse de cada tribunal em destinar, preferencialmente, recursos da verba orçamentária para a implementação de sistemas processuais eletrônicos. Tanto é que a inserção do processo judicial eletrônico ocorreu de maneira desordenada, à medida que se compara os setores do Poder Judiciário que detêm maior recurso orçamentário de modo decrescente: a Justiça do Trabalho, a Justiça Federal e, por último, a Justiça Estadual. Há, então, um cenário em que se exige cautela para monitorar diversos procedimentos informatizados recém-implantados por alguns tribunais, em contraposição à ausência total de informatização em outros (ATHENIENSE, 2010, p. 81-82).

Concomitantemente, visualiza-se a participação expressiva da iniciativa privada no mercado destinado ao desenvolvimento de sistemas processuais eletrônicos, o que gera vicissitudes no gerenciamento do processo judicial. Isso porque as empresas responsáveis pelos sistemas eletrônicos, assim como por seu gerenciamento, seus provedores e seus servidores, provavelmente serão distintas nos vários Estados da Federação. Com isso, haverá certa dificuldade na leitura e na decodificação dos sistemas eletrônicos para efeitos de consulta e utilização do banco de dados (ABRÃO, 2017, p. 73).

Outra legislação referente ao tema é o Código de Processo Civil, Lei n. 13.105/2015, que estabeleceu relevantes alterações no âmbito do sistema processual. No que diz respeito à informatização em específico, a lei ratificou, na esfera do processo de conhecimento, a realização de vários atos processuais pelo meio eletrônico, permitindo a realização de audiência de conciliação ou de mediação também pela via eletrônica; na esfera do processo de execução, regulamentou o leilão eletrônico; e, na esfera recursal, inaugurou o registro eletrônico dos incidentes de resolução de demandas repetitivas e dos recursos especial e extraordinário repetitivos perante o CNJ, visando a sua ampla divulgação e sua publicidade, além de evitar sobrestamentos indevidos.

Todas essas ações legislativas podem ser visualizadas como mecanismos que intencionam adicionar celeridade e eficiência no processo judicial, na toada da Reforma Judicial realizada pela EC n. 45/2004. A modernização ocorre em resposta à apontada crise de confiança e de 
gestão do Judiciário perante as novas demandas e tecnologias trazidas pela modernidade. A ideia por trás da reforma também parte da corrente teórica do "acesso à Justiça”, frente que busca abrangência máxima da tutela judicial, seja por sua agilidade, seja por sua familiaridade, negando que ela sirva somente a uma parcela da população.

Nesse viés, a expressão "acesso à Justiça” pode ser definida a partir de duas funções desempenhadas pelo sistema jurídico, uma vez entendido como o sistema pelo qual as pessoas podem reivindicar seus direitos e/ou resolver seus litígios sob os auspícios do Estado. A primeira delas é que esse sistema deve ser igualmente acessível a todos, e a segunda é que ele deve produzir resultados que sejam individual e socialmente justos. $\mathrm{O}$ direito ao acesso efetivo à Justiça tem sido progressivamente reconhecido como essencial entre os novos direitos individuais e sociais, uma vez que a titularidade de direitos é destituída de sentido na ausência de mecanismos para sua efetiva reivindicação (CAPPELLETTI e GARTH, 1988, p. 8-12).

Acesso à Justiça é um direito fundamental, na medida em que a Constituição Federal de 1988 consagrou-o em seu art. 5º inciso XXXV: “a lei não excluirá da apreciação do Poder Judiciário lesão ou ameaça a direito”. O direito de acesso à Justiça não significa apenas recurso ao Poder Judiciário sempre que um direito seja ameaçado. Esse direito envolve uma série de instituições estatais e não estatais, de modo que são vários os mecanismos e instituições que podem atuar em sua concretização, considerando, ao menos, três etapas distintas e interligadas: o ingresso visando à obtenção de um direito, os caminhos posteriores à entrada e, finalmente, a saída (SADEK, 2014, p. 57).

Mauro Cappelletti e Bryant Garth (1988, p. 31-73) exploraram em sua obra esses outros mecanismos - as três "ondas" - que viriam a contribuir na efetivação do acesso à Justiça: (1) a assistência judiciária gratuita àqueles que, em razão de suas condições econômicas e financeiras, dela porventura necessitarem; (2) a representação de interesses difusos; e (3) a instituição de outras técnicas procedimentais (ou mesmo a reforma procedimental), como as formas alternativas de solução de conflitos junto ao sistema jurídico.

Assim, a informatização processual e a proposta de governo aberto poderão compor uma "quarta onda" no direito de acesso à Justiça, na qual o meio eletrônico, ao mesmo tempo que concebido para tornar a tramitação processual mais célere e efetiva, deve garantir transparência e tornar possível o acesso ao próprio processo judicial, uma vez composto por grandes e diversas quantidades de dados e informações sobre os cidadãos. Ao lado disso, surgem alguns novos desafios, como o da inclusão/alfabetização digital e o da proteção de dados pessoais, os quais passam a ser massivamente tratados e manipulados por esses sistemas.

No estudo de caso a seguir serão apresentadas algumas dificuldades inerentes ao direito de acesso à Justiça, as quais apontam que, mesmo com a informatização processual, há insuficiência na abertura e no acesso aos dados do Poder Judiciário brasileiro, especificamente no âmbito da Justiça Federal. 


\section{ESTUDO DE CASO: ACESSO AOS DADOS E ÀS INFORMAÇÕES PROCESSUAIS NOS Tribunais Regionais Federais}

Visando apurar, sob a ótica do governo aberto, como funciona o acesso aos dados e às informações processuais na Justiça Federal brasileira, nesta seção são apresentadas a metodologia empregada e a análise crítica dos resultados embasada no aparato teórico da seção anterior.

\section{I Metodologia}

A metodologia da pesquisa pode ser visualizada a partir de três vertentes: (1) método de abordagem, (2) procedimento e (3) técnicas.

Antes de descrevê-las, convém contextualizar que este trabalho integra uma das fases de um projeto cujo tema central é o processo judicial eletrônico e que contém, em síntese, quatro etapas: (1) levantar o estado da arte do tema a partir de revisões da literatura e da legislação; (2) identificar como a informatização e a automação de atos processuais interferem na celeridade do processo e produzir um relatório com dados estatísticos; (3) validar o relatório com especialistas; e (4) divulgar os resultados com a apresentação e a publicação de trabalhos.

Para concretizar essas etapas, elegeu-se intencionalmente como amostra os processos do tipo execução fiscal e a esfera da Justiça Federal, por refletirem menor diversidade de trâmites processuais e por lidarem sempre com entes da União Federal como parte, razão pela qual têm procedimentos semelhantes, isto é, comparáveis entre si.

Este artigo está inserido na segunda fase do projeto, na qual a equipe de pesquisa, ao buscar obter, perante os cinco Tribunais Regionais Federais (TRFs), números processuais de autos já tramitados para consulta de movimentações e datas, deparou-se com entraves relacionados aos temas expostos na revisão bibliográfica (governo aberto, LAI, acesso à Justiça e processo judicial eletrônico). Essa dificuldade na obtenção dos dados e das informações processuais pretendidos geraram metadados cuja análise motivou o presente estudo de caso.

Assim, o método de abordagem consistiu no indutivo, uma vez que foi possível inferir conhecimento atual sobre o governo aberto e acesso à informação no Poder Judiciário brasileiro a partir dos metadados obtidos. O procedimento adotado foi o estudo de caso, que, como intitulado nesta seção, pretendeu averiguar, dentro da temática apresentada, como funciona o acesso a dados e informações processuais na Justiça Federal. E as técnicas, por sua vez, envolveram a consulta pública via portais eletrônicos dos TRFs, o envio de dúvidas via solicitação formal (ofício) e via contato telefônico. Essas técnicas serão detalhadas na seção 2.2.

O período de coleta desses dados deu-se entre março e agosto de 2018. A análise e a discussão dos resultados (metadados) ocorreram de modo qualitativo, com cada observação recaindo sobre um critério na maneira em que eles foram obtidos, quais sejam: a agilidade no retorno das solicitações formais; a diversidade de órgãos internos contatados para a obtenção de dados; o grau de informatização dos processos judiciais; a transparência no retorno das solicitações formais; e a burocracia no manejo das solicitações formais. Elencaram-se essas categorias em razão de serem as que permitiriam transformar esses dados e informações 
processuais em conhecimento útil aos fins do governo aberto, possibilitando a compreensão pelo cidadão acerca do processo judicial, além do potencial de utilização em grande escala desses dados e informações processuais para produzir conhecimento acerca do desempenho e da gestão do Poder Judiciário.

Por fim, tendo em vista que o objetivo é demonstrar em que medida o acesso a dados e informações processuais enfrenta dificuldades, e quais são elas, os metadados foram organizados em quadros e gráficos, a serem visualizados nas seções 2.2 e 2.3.

\subsection{TÉCNICAS EMPREGADAS E RESULTADOS}

2.2. I ObTençÃo dos números de Processos via consulta pública

A primeira técnica de pesquisa consistiu em obter números de processos de execução fiscal com baixa definitiva em 2016 via portais eletrônicos de consulta pública processual dos cinco TRFs brasileiros. Para tanto, foram utilizados os termos de busca "UNIÃO FEDERAL" ou “UNIÃO" no campo destinado ao nome das partes. Os resultados obtidos estão organizados no Quadro 1.

QUADRO 1 - RETORNO DA CONSULTA PÚBLICA PROCESSUAL SIMPLES

TRIBUNAL RESULTADO DA BUSCA INFORMAC̣̃̃ES FORNECIDAS

OBSERVAC̣̃̃ES

\begin{tabular}{lll}
\hline TRF1 NEGATIVO & UNIÃO FEDERAL OU UNIÃO: “MAIS DE 500 & \\
& PARTES FORAM ENCONTRADAS INICIANDO & \\
& COM O ARGUMENTO INFORMADO. POR FAVOR, & \\
& REFINE A SUA PESQUISA”. & \\
\hline TRF2 NEGATIVO & UNIÃO FEDERAL: “A CONSULTA NÃO ESTÁ & FOI POSSÍVEL A \\
& DISPONÍVEL PARA ESTE NOME PORQUE & CONSULTA VIA \\
& TRAZ UMA QUANTIDADE MUITO GRANDE & NÚMERO DE \\
& DE PROCESSOS. INFORME UM NOME MAIS & REGISTRO NA OAB. \\
& COMPLETO OU CONSULTE POR NÚMERO & \\
& DO PROCESSO OU CPF/CNPJ”. & \\
& UNIÃO: “É OBRIGATÓRIO PREENCHER 2 & FOI POSSÍVEL A \\
& PARTES VÁLIDAS DE NOMES PARA FAZER & CONSULTA VIA \\
& CONSULTA POR NOME”. & NÚMERO DE \\
& & REGISTRO NA OAB
\end{tabular}

(continua) 
TRIBUNAL RESULTADO DA BUSCA INFORMAC̣ÕES FORNECIDAS

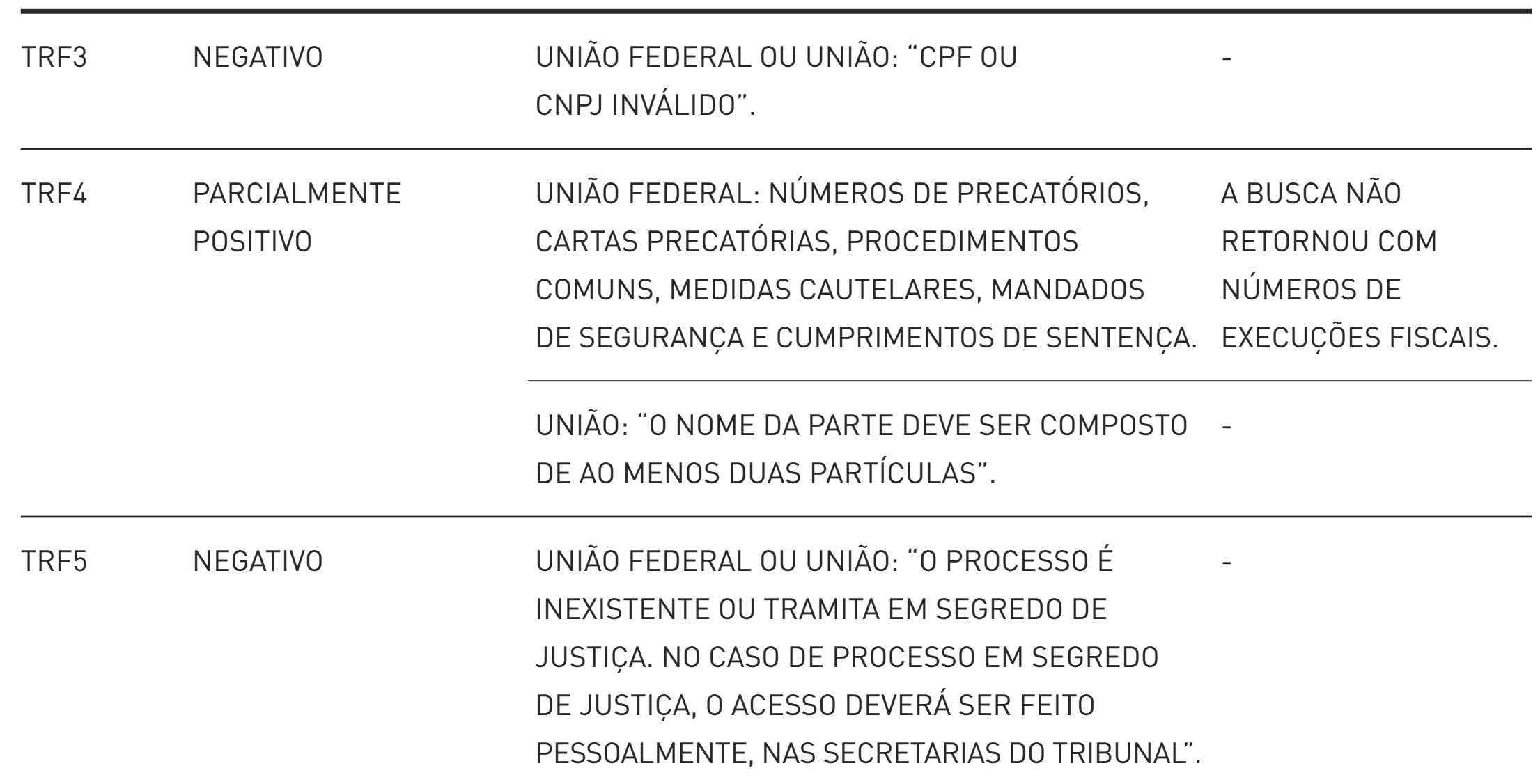

Fonte: Elaborado pelos autores.

Em que pese esta ser a designação correta para a União enquanto parte processual, não houve êxito na obtenção de números de execuções fiscais por meio da consulta processual realizada diretamente nos portais eletrônicos de cada TRF. O fato de não ser possível consultar somente por nome da parte, em se tratando de processos condizentes com atuação da União Federal, pode ser justificado pela matéria tributária, que envolve, em relação ao cidadão, algum nível de sigilo, devido a possíveis situações constrangedoras que esse tipo de causa pode gerar e à cultura de privacidade financeira que permeia a sociedade.

Entretanto, outros processos nos quais figura a União como parte, que não envolvam questões sigilosas, poderiam estar disponíveis para consulta pública, permitindo à sociedade civil tomar conhecimento dessas causas e de seu teor. Ademais, técnicas de anonimização automatizada em relação ao nome das partes poderiam ser adotadas a fim de possibilitar o conhecimento público de causas tributárias, tomando-se as devidas precauções a fim de não gerar reidentificação do cidadão e possível discriminação - problema relatado na jurisprudência espanhola por Galindo (2017, p. 116). ${ }^{3}$

3 Galindo (2017) fala sobre a grande quantidade de processos judiciais espanhóis encontrados em uma busca jurisprudencial pela palavra "cigano”. Ele relata que tal palavra é usada nesses processos para identificar indivíduos, discute a falta de adequação das soluções jurídicas para lidar com minorias raciais e argumenta que isso é um entrave à automatização da justiça meramente baseada em eficiência. 


\subsubsection{ObTENÇÃo dos Números de PROCESSOS Via SOLICITAÇÃo FORMAL E Via CONTATO} TELEFÔNICO

A segunda técnica de pesquisa foi o envio de solicitação formal (ofício) a cada tribunal solicitando o número de cinco processos de execução fiscal com baixa definitiva em 2016, de cada uma das seções judiciárias. Esse encaminhamento foi precedido de contato telefônico ao número de contato geral e/ou da ouvidoria disponibilizado no portal eletrônico, no sentido de verificar qual órgão/setor interno era adequado para atender à solicitação. Os resultados obtidos estão organizados nos Quadros 2 e 3.

QUADRO 2 - RETORNO DOS OFÍCIOS (PRIMEIRA TENTATIVA)

\begin{tabular}{lllll} 
TRIBUNAL & DATA DE ENVIO & ÓRGÃO/SETOR INTERNO & DATA DE RESPOSTA & RESULTADO \\
\hline TRF1 & $04 / 04 / 2018$ & OUVIDORIA & $05 / 04 / 2018$ & NEGATIVO \\
\hline TRF2 & $04 / 04 / 2018$ & PRESIDÊNCIA & - & IGNORADO \\
\hline TRF3 & $04 / 04 / 2018$ & PRESIDÊNCIA & - & IGNORADO \\
\hline TRF4 & $28 / 03 / 2018$ & DIRETORIA JUDICIÁRIA $(*)$ & $03 / 04 / 2018$ & POSITIVO \\
\hline TRF5 & $04 / 04 / 2018$ & OUVIDORIA/CORREGEDORIA & $06 / 04 / 2018$ & NEGATIVO
\end{tabular}

(*) OTribunal estava de recesso na data do contato, de modo que a solicitação foi enviada por meio do plantão judiciário.

Fonte: Elaborado pelos autores.

QUADRO 3 - RETORNO dOS OFÍCIOS (SEGUNDA TENTATIVA)

\begin{tabular}{|c|c|c|c|c|}
\hline TRIBUNAL & DATA DE ENVIO & ÓRGÃO/SETOR INTERNO & DATA DE RESPOSTA & RESULTADO \\
\hline \multirow[t]{4}{*}{ TRF1 } & $06 / 04 / 3018$ & PRESIDÊNCIA & 18/04/2018 (JFAC) (*) & \multirow{4}{*}{$\begin{array}{l}\text { PARCIALMENTE } \\
\text { POSITIVO }\end{array}$} \\
\hline & & & 30/04/2018 (JFDF) (*) & \\
\hline & & & 25/05/2018 (JFRO) (*) & \\
\hline & & & 15/08/2018 (JFMT E JFM & \\
\hline
\end{tabular}

(continua) 


\begin{tabular}{lllll} 
TRIBUNAL & DATA DE ENVIO & ÓRGÃO/SETOR INTERNO & DATA DE RESPOSTA & RESULTADO \\
\hline TRF2 & $28 / 06 / 2018$ & $\begin{array}{l}\text { SERVIC̦O DE INFORMAÇÃO } \\
\text { AO CIDADÃO }(S I C)\end{array}$ & $23 / 08 / 2018$ & POSITIVO \\
\hline TRF3 & $28 / 06 / 2018$ & OUVIDORIA/SIC & $11 / 07 / 2018$ & POSITIVO \\
\hline TRF4 & - & - & - & - \\
\hline TRF5 & $28 / 06 / 2018$ & SIC & $04 / 07 / 2018$ & POSITIVO
\end{tabular}

(*) A solicitação foi distribuída às seções judiciárias.

Fonte: Elaborado pelos autores.

É possível observar que, na primeira tentativa (Quadro 2), a solicitação foi direcionada para diferentes canais em cada TRF, conforme orientado pelo contato telefônico, ao passo que somente um deles retornou (oTRF4). Na segunda tentativa (Quadro 3), foram acionados outros canais, diversos da primeira tentativa, e assim a equipe obteve retorno na solicitação. O resultado é que a mesma solicitação foi processada por canais distintos entre os TRFs contatados.

\subsubsection{Consulta PÚblica dos PROCESSOS OBTIDOS E ENCAMINHAMENTO DE DÚvidAS POSTERIORES} Obtidos os números processuais almejados, a terceira técnica de pesquisa consistiu na consulta pública desses processos, quando surgiram dúvidas em relação às diferentes nomenclaturas dadas aos trâmites e ao suporte pelo qual o processo havia, de fato, tramitado (se físico, eletrônico ou híbrido), bem como se algumas movimentações eram de responsabilidade de servidores ou do sistema eletrônico. Por esse motivo, foram realizados novos contatos telefônicos e encaminhados novos ofícios a algumas varas federais com dúvidas específicas, cujas informações recebidas estão organizadas nos Quadros 4 e 5. 
QUADRO 4 - DÚVIDAS APRESENTADAS VIA TELEFONE

\begin{tabular}{|c|c|c|c|c|}
\hline \multirow{2}{*}{ TRIBUNAL } & \multirow[b]{2}{*}{ VARA } & \multirow{2}{*}{$\begin{array}{l}\text { DATA DO CONTATO } \\
\text { TELEFÔNICO }\end{array}$} & \multirow[b]{2}{*}{ DÚVIDAS } & \multirow[b]{2}{*}{ INFORMAC̣ÕES FORNECIDAS } \\
\hline & & & & \\
\hline \multirow[t]{2}{*}{ TRF1 } & $\begin{array}{l}1 \text { a VARA } \\
\text { FEDERAL DE } \\
\text { RIO BRANCO/AC }\end{array}$ & $02 / 07 / 2018$ & $\begin{array}{l}\text { A) OS PROCESSOS } \\
\text { SÃO FÍSICOS, } \\
\text { ELETRÔNICOS } \\
\text { OU HÍBRIDOS? }\end{array}$ & $\begin{array}{l}\text { A DIGITALIZAÇÃO E A INFORMATIZAÇÃO } \\
\text { DOS PROCESSOS INICIARAM-SE EM } \\
\text { 2016. PORÉM, OS PROCESSOS DE } \\
\text { EXECUÇÃO FISCAL AINDA SÃO } \\
\text { INTEGRALMENTE FÍSICOS. }\end{array}$ \\
\hline & $\begin{array}{l}\text { 11a VARA } \\
\text { FEDERAL DE } \\
\text { BRASÍLIA/DF }\end{array}$ & 02/07/2018 & $\begin{array}{l}\text { A) OS PROCESSOS } \\
\text { SÃO FÍSICOS, } \\
\text { ELETRÔNICOS } \\
\text { OU HÍBRIDOS? }\end{array}$ & $\begin{array}{l}\text { A DIGITALIZAÇÃO E A INFORMATIZAÇÃO } \\
\text { DOS PROCESSOS INICIARAM-SE EM } \\
\text { 2009. PORÉM, OS PROCESSOS DE } \\
\text { EXECUÇÃO FISCAL CONSULTADOS } \\
\text { (ANOS 2011 E 2012) INICIARAM-SE } \\
\text { VIA FÍSICA (PROTOCOLO PELO } \\
\text { PROCURADOR, DISTRIBUICCÃO E } \\
\text { AUTUAÇÃO PELO SERVIDOR DO PODER } \\
\text { JUDICIÁRIO) E LOGO APÓS FORAM } \\
\text { DIGITALIZADOS, PORQUANTO SÃO } \\
\text { HÍBRIDOS. }\end{array}$ \\
\hline \multirow[t]{2}{*}{ TRF2 } & $\begin{array}{l}2^{\text {a }} \text { VARA } \\
\text { FEDERAL DO RIO } \\
\text { DE JANEIRO/RJ }\end{array}$ & $27 / 08 / 2018$ & $\begin{array}{l}\text { A) OS PROCESSOS } \\
\text { SÃO FÍSICOS, } \\
\text { ELETRÔNICOS } \\
\text { OU HÍBRIDOS? } \\
\text { B) O QUE SIGNIFICA } \\
\text { "REDISTRIBUIÇÃO"? }\end{array}$ & $\begin{array}{l}\text { A DIGITALIZAÇ̃̃O E A INFORMATIZAÇÃO } \\
\text { DOS PROCESSOS INICIARAM-SE EM } \\
\text { 2013. OS PROCESSOS CONSULTADOS } \\
\text { SÃO FÍSICOS E ELETRÔNICOS. } \\
\text { AS FASES PROCESSUAIS DENOMINADAS } \\
\text { DE “REDISTRIBUIĊÃO” PODEM ESTAR } \\
\text { RELACIONADAS À CRIAÇÃOO DE VARAS } \\
\text { FEDERAIS ESPECÍFICAS DE } \\
\text { EXECUÇÕES FISCAIS. }\end{array}$ \\
\hline & $\begin{array}{l}1 \text { a VARA } \\
\text { FEDERAL DE } \\
\text { SÃO MATEUS/ES }\end{array}$ & $27 / 08 / 2018$ & $\begin{array}{l}\text { A) OS PROCESSOS } \\
\text { SÃO FÍSICOS, } \\
\text { ELETRÔNICOS } \\
\text { OU HÍBRIDOS? } \\
\text { B) O QUE SIGNIFICA } \\
\text { "REDISTRIBUIÇÃO”? }\end{array}$ & $\begin{array}{l}\text { A DIGITALIZAÇÃO E A INFORMATIZAÇÃO } \\
\text { DOS PROCESSOS INICIARAM-SE EM } 2010 . \\
\text { OCORREU ANTES EM RELAÇÃO AO RJ } \\
\text { POIS O PROJETO-PILOTO DO “APOLO” } \\
\text { (SISTEMA UTILIZADOI É ORIUNDO DO } \\
\text { ES. OS PROCESSOS CONSULTADOS } \\
\text { SÃO FÍSICOS. } \\
\text { AS FASES PROCESSUAIS DENOMINADAS } \\
\text { DE “REDISTRIBUIÇÃO” PODEM ESTAR } \\
\text { RELACIONADAS À CRIAÇÃO DE VARAS } \\
\text { FEDERAIS ESPECÍFICAS DE EXECUÇÕES } \\
\text { FISCAIS. }\end{array}$ \\
\hline
\end{tabular}


DATA DO CONTATO

TRIBUNAL VARA TELEFÔNICO

DÚVIDAS

A) OS PROCESSOS

SÃO FÍSICOS,

ELETRÔNICOS

OU HÍBRIDOS?

\section{INFORMAC̣ÕES FORNECIDAS}

A DIGITALIZAÇÃO E A INFORMATIZAC̣ÃO

DOS PROCESSOS INICIARAM-SE EM 2017,

DE MODO QUE OS PROCESSOS

CONSULTADOS SÃO FÍSICOS.

NOS PROCESSOS FÍSICOS, A

DIGITALIZAÇÃO OCORRE APENAS EM

CASO DE RECURSO E DE CUMPRIMENTO

DE SENTENÇA.
TODOS OS PROCESSOS CONSULTADOS

SÃO ELETRÔNICOS. (*)

AIOS PROCESS

SÃO FÍSICOS,

SÃOELETRONICOS. (*)

\begin{tabular}{|c|c|c|c|c|}
\hline TRF4 & - & - & $\begin{array}{l}\text { A) OS PROCESSOS } \\
\text { SÃO FÍSICOS, } \\
\text { ELETRÔNICOS } \\
\text { OU HÍBRIDOS? }\end{array}$ & $\begin{array}{l}\text { TODOS OS PROCESSOS CONSULTADOS } \\
\text { SÃO ELETRÔNICOS. (*) }\end{array}$ \\
\hline TRF5 & $\begin{array}{l}4^{\mathrm{a}} \text { VARA } \\
\text { FEDERAL } \\
\text { DE ARACAJU }\end{array}$ & $13 / 07 / 2018$ & $\begin{array}{l}\text { A) OS PROCESSOS } \\
\text { SÃO FÍSICOS, } \\
\text { ELETRÔNICOS } \\
\text { OU HÍBRIDOS? }\end{array}$ & $\begin{array}{l}\text { A DIGITALIZAÇÃO E A INFORMATIZAÇÃO } \\
\text { DOS PROCESSOS INICIARAM-SE EM } \\
\text { SETEMBRO DE 2016, DE MODO QUE } \\
\text { OS PROCESSOS DE EXECUC̣ÃO FISCAL } \\
\text { CONSULTADOS (ANOS } 2007 \text { A 2015) } \\
\text { SÃO FÍSICOS. }\end{array}$ \\
\hline
\end{tabular}

(*) A consulta foi facilitada por meio do número de registro na OAB de um dos autores.

Fonte: Elaborado pelos autores. 
QUADRO 5 - DÚVIDAS APRESENTADAS VIA OFÍCIO

\begin{tabular}{|c|c|c|c|c|c|}
\hline TRIBUNAL & VARA & $\begin{array}{l}\text { DATA } \\
\text { DO ENVIO }\end{array}$ & DÚVIDAS & $\begin{array}{l}\text { DATA DE } \\
\text { RESPOSTA }\end{array}$ & $\begin{array}{l}\text { INFORMAC̣õES } \\
\text { RECEBIDAS }\end{array}$ \\
\hline \multirow[t]{4}{*}{ TRF1 } & $\begin{array}{l}\text { 1 a VARA } \\
\text { FEDERAL } \\
\text { DE RIO } \\
\text { BRANCO/AC }\end{array}$ & 08/08/2018 & $\begin{array}{l}\text { O QUE SIGNIFICA A FASE } \\
\text { PROCESSUAL “DISTRIBUIÇÃO } \\
\text { AUTOMÁTICA”? HÁ ALGUM } \\
\text { SISTEMA DE SUPORTE E/OU } \\
\text { GESTÃO DOS PROCESSOS FÍSICOS? }\end{array}$ & 08/08/2018 & $\begin{array}{l}\text { O OFÍCIO FOI } \\
\text { ENCAMINHADO AO SETOR } \\
\text { DE DISTRIBUIÇÃO, PORÉM } \\
\text { APÓS ISSO FOI IGNORADO. }\end{array}$ \\
\hline & $\begin{array}{l}2^{\text {a VARA }} \\
\text { FEDERAL } \\
\text { DE RIO } \\
\text { BRANCO/AC }\end{array}$ & 09/08/2018 & $\begin{array}{l}\text { O QUE SIGNIFICA A FASE } \\
\text { PROCESSUAL “DISTRIBUIÇÃO } \\
\text { AUTOMÁTICA”? HÁ ALGUM } \\
\text { SISTEMA DE SUPORTE E/OU } \\
\text { GESTÃO DOS PROCESSOS FÍSICOS? }\end{array}$ & $10 / 08 / 2018$ & $\begin{array}{l}\text { A DISTRIBUIÇÃO É FEITA } \\
\text { PRESENCIALMENTE, } \\
\text { PORÉM ATRAVÉS DO } \\
\text { SISTEMA PROCESSUAL } \\
\text { ORACLE, E A GESTÃO } \\
\text { DOS PROCESSOS FÍSICOS } \\
\text { SE FAZ ATRAVÉS DESSE } \\
\text { MESMO SISTEMA. }\end{array}$ \\
\hline & $\begin{array}{l}\text { 3a VARA } \\
\text { FEDERAL } \\
\text { DE RIO } \\
\text { BRANCO/AC }\end{array}$ & 09/08/2018 & $\begin{array}{l}\text { O QUE SIGNIFICA A FASE } \\
\text { PROCESSUAL “DISTRIBUICCÃO } \\
\text { AUTOMÁTICA”? HÁ ALGUM } \\
\text { SISTEMA DE SUPORTE E/OU } \\
\text { GESTÃO DOS PROCESSOS FíSICOS? }\end{array}$ & - & IGNORADO. \\
\hline & $\begin{array}{l}11^{\text {a }} \text { VARA } \\
\text { FEDERAL DE } \\
\text { BRASÍLIA/DF }\end{array}$ & $06 / 08 / 2018$ & $\begin{array}{l}\text { O QUE SIGNIFICAM AS FASES } \\
\text { PROCESSUAIS “DISTRIBUICCÃO } \\
\text { AUTOMÁTICA” E “CARGA } \\
\text { RETIRADOS FAZENDA NACIONAL”? } \\
\text { AS NOMENCLATURAS DAS } \\
\text { MOVIMENTAÇÕES RELATIVAS } \\
\text { AOS PROCESSOS FÍSICOS E AOS } \\
\text { PROCESSOS ELETRÔNICOS SÃO } \\
\text { AS MESMAS? } \\
\text { HÁ DIFERENÇA ENTRE AS FASES } \\
\text { “RECEBIDOS PELO DIRETOR } \\
\text { SECRETARIA” E “RECEBIDOS } \\
\text { EM SECRETARIA”? } \\
\text { COMO É FEITA A JUNTADA DE } \\
\text { PETIÇÕES E DOCUMENTOS PELO } \\
\text { PROCURADOR E PELOS DEMAIS }\end{array}$ & - & IGNORADO. \\
\hline
\end{tabular}

(continua) 


\begin{tabular}{|c|c|c|c|}
\hline & DATA & DATA DE & INFORMAC̣ÕES \\
\hline TRIBUNAL VARA & DO ENVIO DÚVIDAS & RESPOSTA & RECEBIDAS \\
\hline
\end{tabular}

\begin{tabular}{|c|c|c|c|c|}
\hline & & & $\begin{array}{l}\text { AGENTES EXTERNOS? } \\
\text { QUEM CERTIFICA O TRÂNSITO } \\
\text { EM JULGADO? } \\
\text { EXISTE UMA LISTA DE } \\
\text { MOVIMENTAÇÕES PROCESSUAIS } \\
\text { QUE OCORREM DE MANEIRA } \\
\text { AUTOMÁTICA? }\end{array}$ & \\
\hline TRF2 & - & - & - & - \\
\hline TRF3 & $\begin{array}{l}\text { 6a VARA } \\
\text { FEDERAL } \\
\text { DE CAMPO } \\
\text { GRANDE/MS }\end{array}$ & 08/08/2018 & $\begin{array}{l}\text { O QUE SIGNIFICA A FASE } \\
\text { PROCESSUAL “DISTRIBUIÇÃO/ } \\
\text { ATRIBUIÇÃO ORDINÁRIA } \\
\text { INSTANTÂNEA”? } \\
\text { HÁ ALGUM SISTEMA DE SUPORTE } \\
\text { E/OU GESTÃO DOS PROCESSOS } \\
\text { FíSICOS? }\end{array}$ & IGNORADO \\
\hline TRF4 & $\begin{array}{l}19 \text { a VARA } \\
\text { FEDERAL DE } \\
\text { CURITIBA/PR }\end{array}$ & $13 / 08 / 2018$ & $\begin{array}{l}\text { A EXPEDIÇÃO DA REQUISIÇÃO } \\
\text { DE PEQUENO VALOR (RPV) } \\
\text { É REALIZADA DE MANEIRA } \\
\text { AUTOMÁTICA PELO SISTEMA EPROC? } \\
\text { HÁ DILIGÊNCIAS PROCESSUAIS } \\
\text { QUE SÃO REALIZADAS } \\
\text { AUTOMATICAMENTE POR ESSE } \\
\text { SISTEMA? }\end{array}$ & IGNORADO. \\
\hline
\end{tabular}

TRF5

Fonte: Elaborado pelos autores.

É necessário pontuar que a consulta pública às execuções fiscais ocorreu através de diferentes sistemas (quanto aos processos eletrônicos e híbridos), quais sejam, "Processo Judicial Digital” - PJD (TRF1), “Apolo" (TRF2) e "Processo Eletrônico" - Eproc (TRF4). Isso reflete o exposto na revisão bibliográfica quanto à diversidade de sistemas eletrônicos decorrente do ingresso da iniciativa privada nesse ramo do Poder Judiciário.

\subsection{AnÁlise e discussão dos ReSUltados}

Para melhor análise e discussão do caso em estudo, como exposto na metodologia, os resultados foram organizados a partir de cinco critérios: (1) a agilidade no retorno das solicitações 
encaminhadas pela equipe, comparando-se o intervalo de dias corridos entre os TRFs; (2) a diversidade de órgãos internos/setores e varas federais que foram acionados e que deram retorno às solicitações encaminhadas pela equipe entre osTRFs; (3) a informatização dos TRFs no que se refere às execuções fiscais, comparando-se a existência de processos físicos, híbridos e eletrônicos neles em trâmite; (4) a transparência na apresentação de resposta, comparando-se, entre os TRFs, os órgãos internos/setores e as varas federais que ignoraram as solicitações encaminhadas pela equipe; e (5) a burocracia constatada na apresentação de resposta, fato ocorrido especificamente no TRF1.

E, para a melhor compreensão dos resultados, partiu-se de conceitos extraídos da doutrina e da legislação pertinentes aos temas expostos, os quais foram escolhidos conforme melhor refletiram nos resultados obtidos.

Assim, por agilidade, considerou-se o tempo suficiente para atender à demanda do cidadão. Ao esclarecer sobre o prazo para fornecimento de informações com base na LAI, a Controladoria-Geral da União pondera que deve haver "equilíbrio entre a necessidade do cidadão e a capacidade de entrega por parte da Administração” (CGU, 2011, p. 20).

$\mathrm{Na}$ informatização, o processo judicial físico é aquele existente em um primeiro momento, representado inteiramente em papel; já o processo judicial híbrido leva esse nome por ter algum instrumento físico em que ou registram-se apenas as movimentações no meio eletrônico, ou os autos já estão digitalizados e circulam pastas físicas os representando; e o processo judicial eletrônico já tem todo o conteúdo e a movimentação processual somente em documentos eletrônicos (BRASIL, 2006; WAMBIER et al., 2015, p. 2.378-2.379).

Com relação à diversidade de órgãos acionados e que forneceram retorno às solicitações, levou-se em conta qual órgão exerceu a competência de cumprir as obrigações e atribuições (MELLO, 2015, p. 143-145) constantes na LAI - se foi a Ouvidoria, a Corregedoria, a Presidência ou o Serviço de Informação ao Cidadão (SIC).

Por "transparência", entendeu-se o direito do cidadão de receber dos órgãos públicos informações de seu interesse particular, ou de interesse coletivo ou geral, a serem prestadas no prazo da lei, sob pena de responsabilidade, ressalvadas aquelas cujo sigilo seja imprescindível à segurança da sociedade e do Estado (BRASIL, 1988; BRASIL, 2011).

Finalmente, concebeu-se por "burocracia" a apreensão excessiva às regulamentações, duplicações desnecessárias de registros e utilização de um alto volume de informações estranhas ou impertinentes que causam atrasos ou inações, isto é, seu sentido pejorativo de ineficiência e morosidade na prestação do serviço público (DENHARDT, 2015, p. 339-340).

\subsection{Agilidade No RETORNO DAS SOlicitaÇões}

Infere-se dos resultados obtidos que oTRF4 e o TRF5 apresentaram as informações solicitadas com maior agilidade, e o TRF2, por sua vez, com menor agilidade. Enquanto isso, das cinco varas federais acionadas, apenas uma delas indicou resposta às dúvidas, ao passo que as demais ignoraram a solicitação. 
O Gráfico 1 demonstra o intervalo, em dias corridos, entre a data da solicitação das informações processuais e a data em que houve o retorno positivo de cada tribunal. Considerou-se, na organização desses resultados, as duas tentativas realizadas (vide Quadros 2 e 3), e o fato de que o TRF1 descentralizou a solicitação entre suas seções judiciárias, das quais três retornaram com as informações requeridas (Acre, Distrito Federal e Rondônia).

\section{GRÁFICO 1 - INTERVALO ENTRE A DATA DA SOLICITAÇÃO DAS INFORMAÇÕES E A DATA DE RETORNO POSITIVO (Q2 E Q3)}

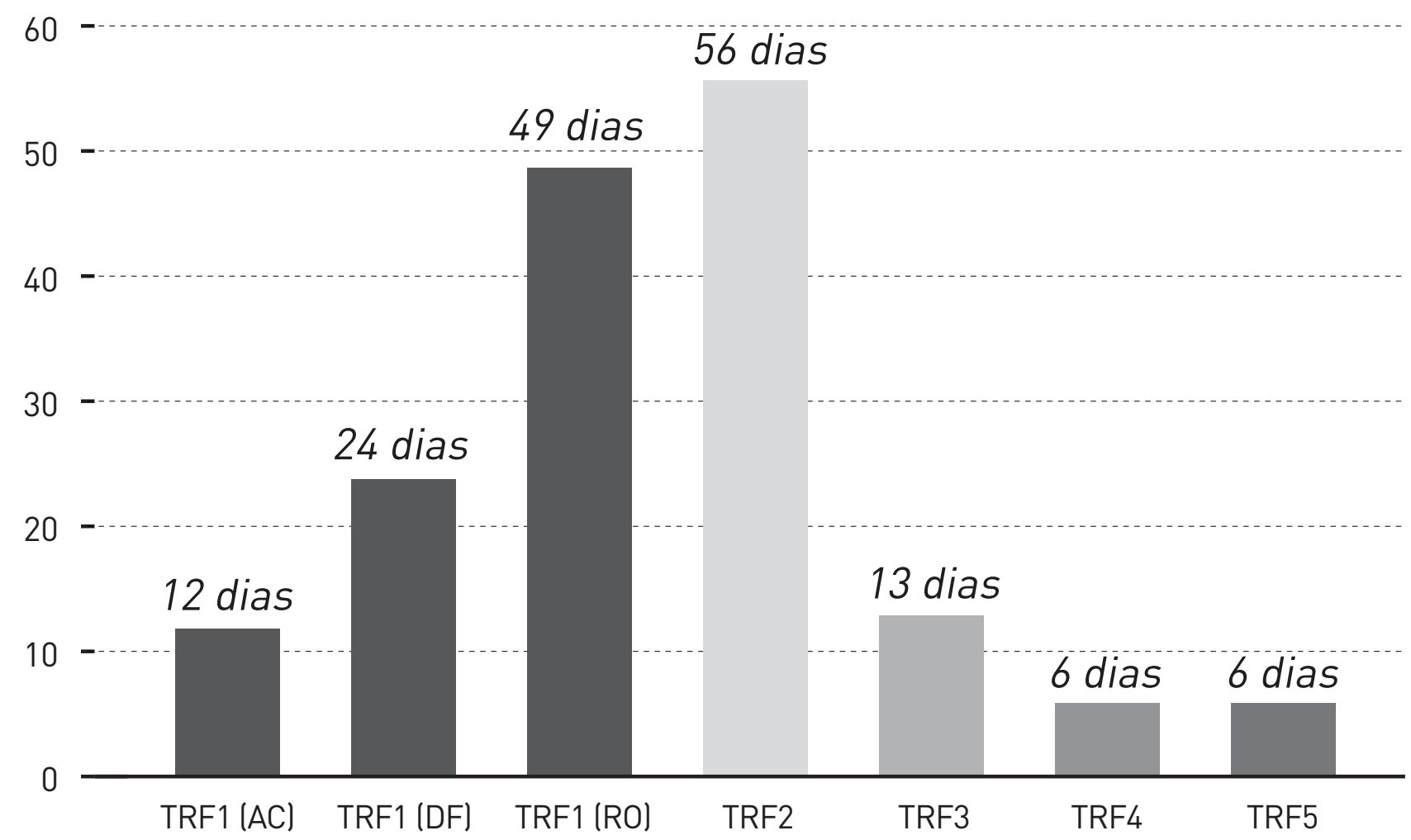

Fonte: Elaborado pelos autores.

Percebe-se falta de padronização no atendimento às solicitações de informações, com diferentes tempos de resposta - o que pode estar vinculado às capacidades de cada tribunal em termos de recursos humanos e materiais disponíveis. A espera por resposta varia entre prazo adequado e não adequado, e, na maioria das vezes, supera uma semana, não atendendo à necessidade levantada - dar andamento ao projeto de pesquisa. Percebe-se ausência de harmonia entre as capacidades dos tribunais e a resultante insuficiência ante as necessidades que deveriam ser atendidas pela proposta de modernização do processo judicial.

O Gráfico 2, por sua vez, demonstra o intervalo, em dias corridos, entre a data de envio das dúvidas específicas às varas federais (vide Quadro 5) e a data em que houve o retorno positivo. 


\section{GRÁFICO 2 - INTERVALO ENTRE A DATA DE ENVIO DAS DÚVIDAS ESPECÍFICAS E A DATA DE RETORNO POSITIVO (Q5)}

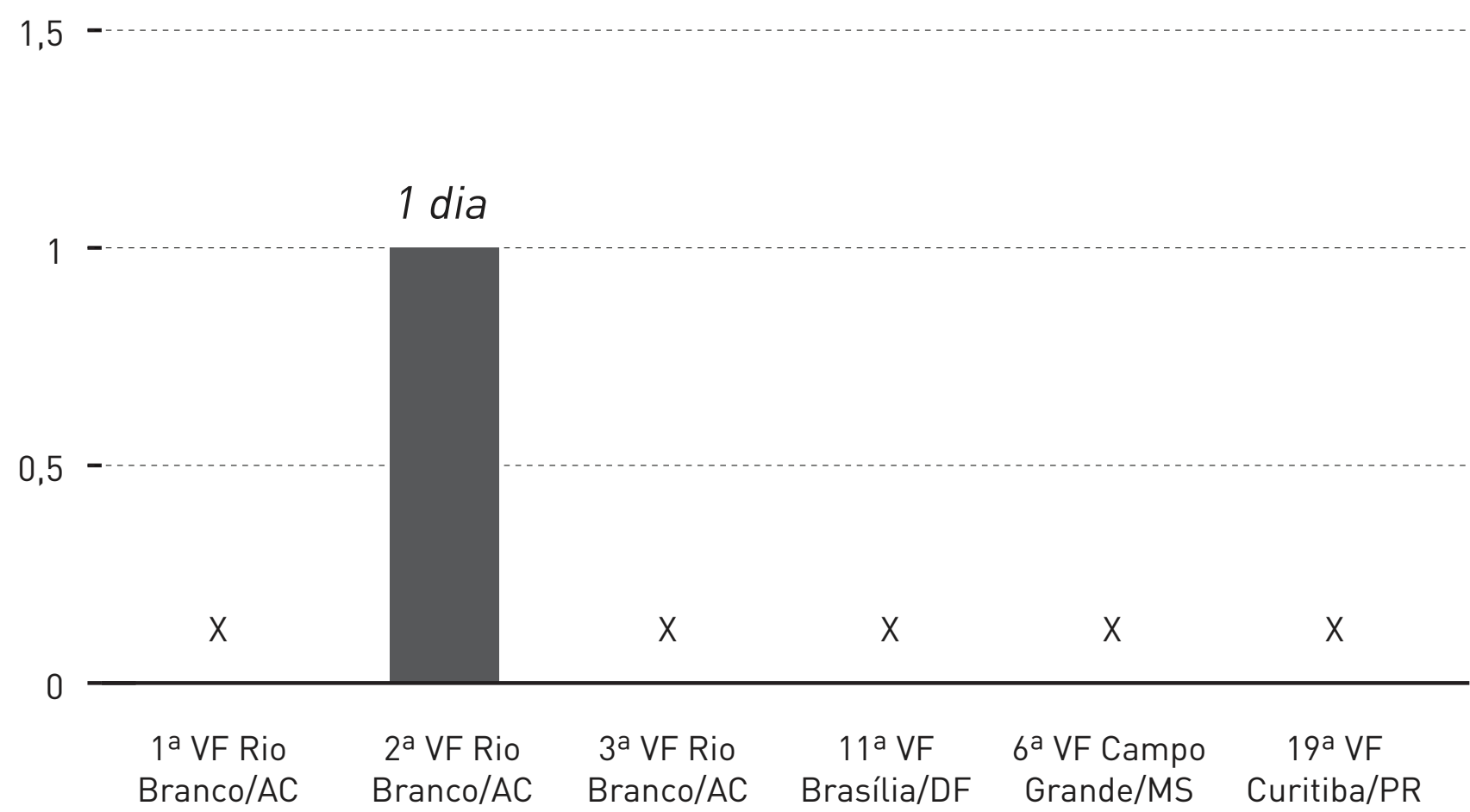

Fonte: Elaborado pelos autores.

\subsubsection{Diversidade nos ÓRgÃos INTERNOS ACIONADOS}

Conforme exposto na descrição dos resultados, diferentes órgãos internos de cada tribunal foram acionados até que se obtivesse o retorno pretendido, quais sejam, Presidência (TRF1, TRF2 e TRF3), Diretoria Judiciária (TRF4), Corregedoria (TRF5), Ouvidoria (TRF1, TRF3 e TRF5) e SIC (TRF2, TRF3 e TRF5) - vide Quadros 2 e 3. Com isso, depreende-se certa diversidade na quantidade de órgãos que retornaram às solicitações, porém predomina o SIC como o órgão adequado para esse tipo de demanda, o que atende às diretrizes da LAI.

O Gráfico 3 apresenta um panorama de quantos e quais órgãos foram acionados no decorrer da pesquisa, bem como qual órgão ofereceu o retorno em cada tribunal, considerando que em alguns tribunais foi constatada a fusão de dois órgãos (o que, para efeitos de quantificação, foi considerado o valor de 0,5$)$ : 
GRÁFICO 3 - ÓRGÃOS INTERNOS DOSTRFS ACIONADOS NO DECORRER DA PESQUISA (Q2 E Q3)

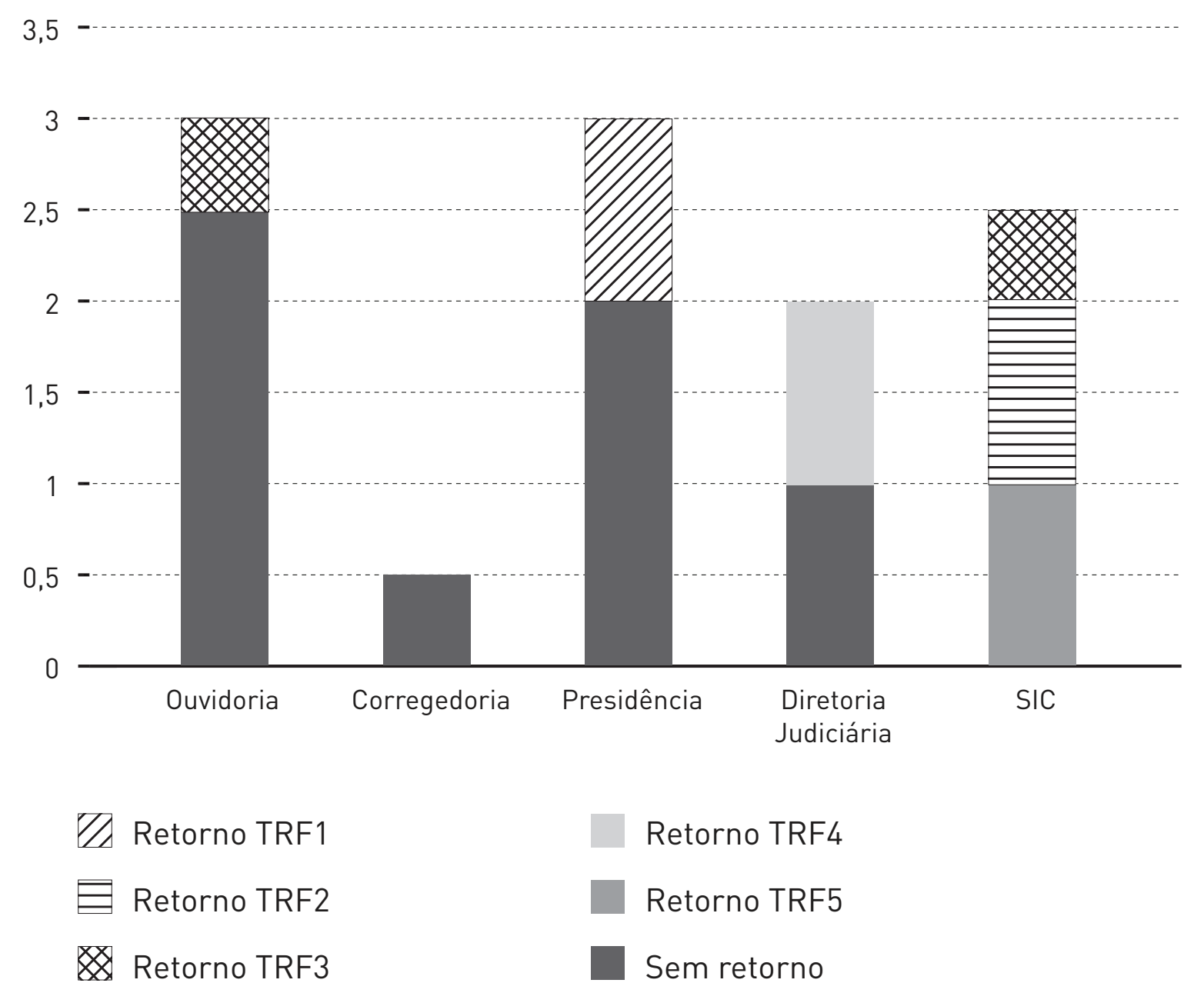

Fonte: Elaborado pelos autores.

Essa diversidade de canais que processaram as solicitações enviadas pode estar relacionada à ausência de governança nos tribunais acionados, sobretudo naqueles que não enviaram o retorno via SIC, em que pese a LAI determinar que esse tipo de requerimento deverá ser analisado por esse canal (art. 9 ${ }^{\circ}$, I, “C”). Isso dificulta o aproveitamento dessa ferramenta comunicacional, reforçando as barreiras existentes entre a sociedade civil e os órgãos governamentais, na medida em que não há canais dispostos e dedicados a atender demandas por esse tipo de informação. Dois problemas são gerados dessa situação: a sobrecarga de setores não capacitados para produzir esses dados e o desincentivo a que os dados sejam buscados pela sociedade para construir conhecimento e transparência acerca dos trâmites processuais.

\section{$2 \cdot 3 \cdot 3$ INFORMATIZAÇÃO DAS EXECUÇÕES FISCAIS}

De acordo com as informações obtidas via telefone (vide Quadro 4), e tendo como parâmetro de pesquisa a amostra dos processos de execução fiscal consultados, é possível aferir o nível de informatização processual dos tribunais pesquisados. Para tanto, considerou-se a existência de processos judiciais físicos, híbridos e eletrônicos em cada TRF. 
O Gráfico 4 apresenta, a partir de três níveis - sendo (1) processo físico, (2) processo híbrido e (3) processo eletrônico -, qual o estágio da informatização processual nos tribunais analisados.

\section{GRÁFICO 4 - NÍVEL DE INFORMATIZAÇÃo DAS EXECUÇÕES FISCAIS (Q4)}

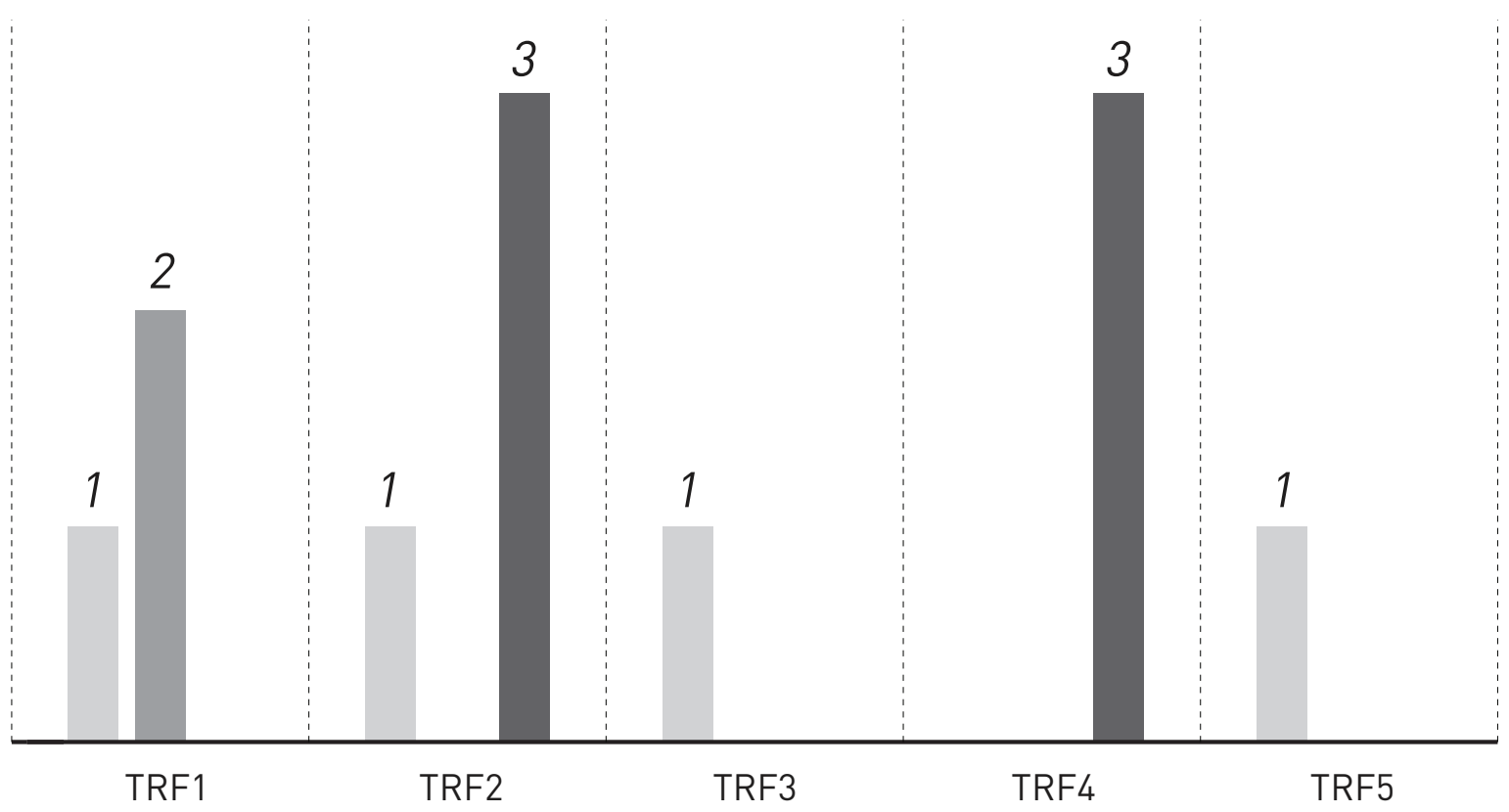
Físico
Híbrido
Eletrônico

Fonte: Elaborado pelos autores.

Depreende-se que, embora a legislação que dispõe sobre a informatização do processo judicial esteja vigente desde 2006, existem, ainda, processos físicos de execução fiscal em trâmite na Justiça Federal, destacando-se que o TRF4 se apresentou como o único em que esses processos tramitam integralmente pelo meio eletrônico. Por outro lado, o TRF3 se apresentou como o único em que os processos de execução fiscal tramitam integralmente pelo meio físico, considerando que a informatização e a digitalização ocorreram de maneira tardia nesse tribunal - isto é, em 2017.

\section{$2 \cdot 3 \cdot 4$ TRANSPARÊNCIA NO RETORNO DAS SOLICITAÇÕES}

No decorrer da obtenção de dados e informações processuais, alguns dos tribunais analisados, representados por seus órgãos internos e por algumas das varas federais demandadas, ignoraram as solicitações encaminhadas pela equipe de pesquisa (vide Quadros 2 e 5). Tais condutas contrariam as disposições da LAI e os princípios de governo aberto. 
O Gráfico 5 quantifica os órgãos internos e as varas federais acionados que não apresentaram retorno às solicitações de dados e informações processuais, sendo possível verificar o nível de transparência, a partir da amostra de pesquisa, nos cinco TRFs:

\section{GRÁFICO 5 - ÓRGÃos INTERNOS EVARAS FEDERAIS QUE NÃO RETORNARAM ÀS SOLICITAÇÕES (Q2 E Q5)}

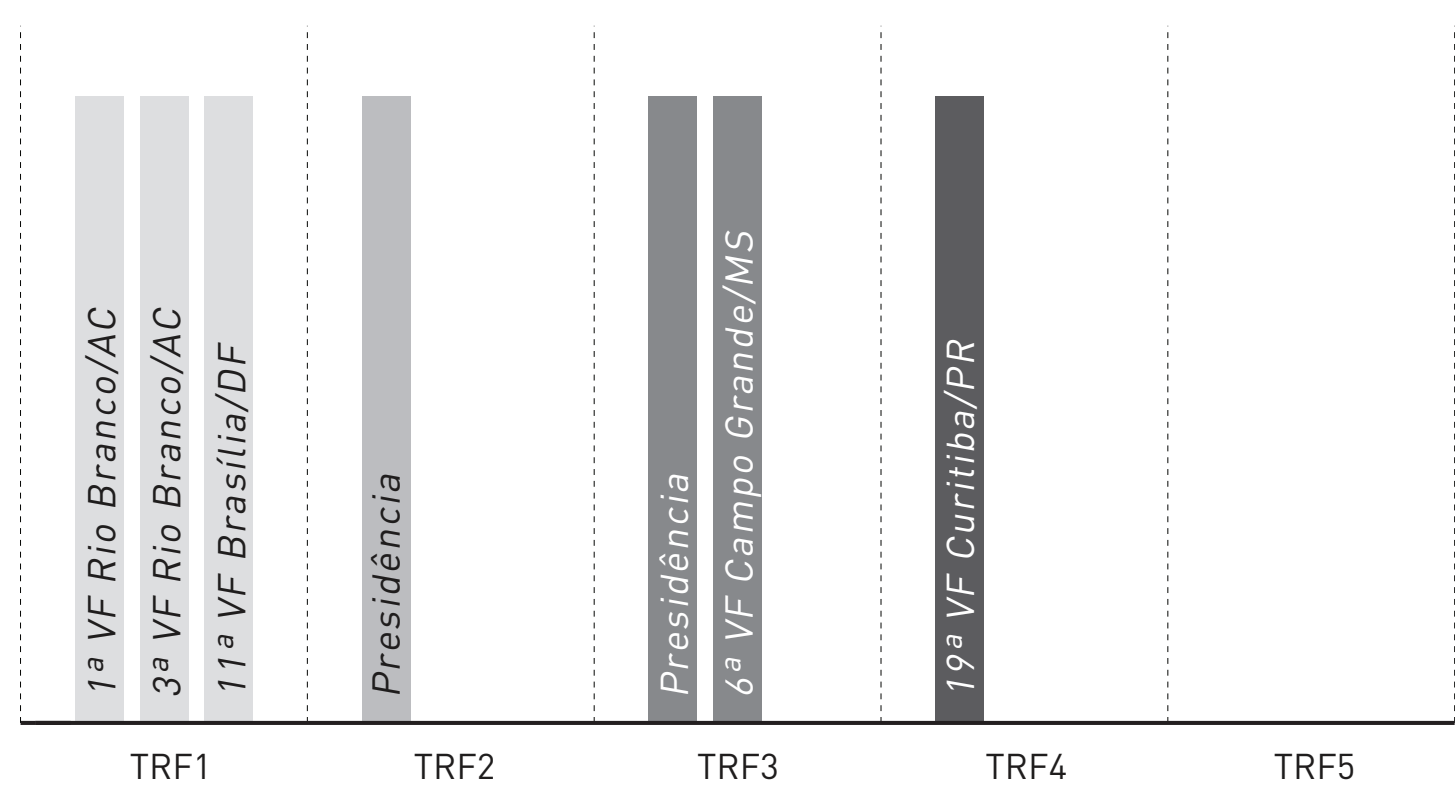

Fonte: Elaborado pelos autores.

Constata-se que, dos órgãos acionados, a Presidência, por duas ocasiões (TRF2 e TRF3), não retornou à solicitação enviada pela equipe de pesquisa, o que também ocorreu com a maior parte das varas federais acionadas (vide Gráfico 2, no qual apenas a $2^{\mathrm{a}}$ Vara Federal de Rio Branco/AC apresentou resposta às dúvidas encaminhadas).

A ausência de atendimento às dúvidas remetidas acerca de informações processuais básicas, como tipo de trâmite e nomenclatura de movimentações processuais, demonstra um quadro de opacidade perante o público. Pode-se levantar como hipóteses para essa negativa tanto a insuficiência quanto a cultura institucional, e apontar uma ou outra como causa demanda estudos junto a esses servidores ou observação do funcionamento interno desses órgãos. Não obstante, é patente a impressão de incapacidade de tradução das práticas institucionais judiciais ao público externo causada pela inércia em responder às dúvidas, gerando uma imagem de complexidade insuperável do funcionamento institucional que afasta o cidadão.

\section{$2 \cdot 3 \cdot 5$ BUROCRACIA NO MANEJO DAS SOlicitaÇÕ̃es}

Além da ausência de retorno por parte de alguns órgãos internos e varas federais, outro fato observado foi a remessa das solicitações a outros órgãos internos ou setores dentro do TRF1, 
ou, ainda, o recebimento da resposta de que determinado órgão interno ou vara não era responsável pelos dados e informações processuais requeridos. Tal fato é reflexo característico da burocracia no serviço público.

A Figura 1 apresenta um diagrama da remessa das solicitações a outros órgãos ou setores internos, ressaltando que esse fato ocorreu predominantemente no TRF1.

\section{FIGURA 1 - REMESSA DAS SOLICITAÇÕES NOTRF I}
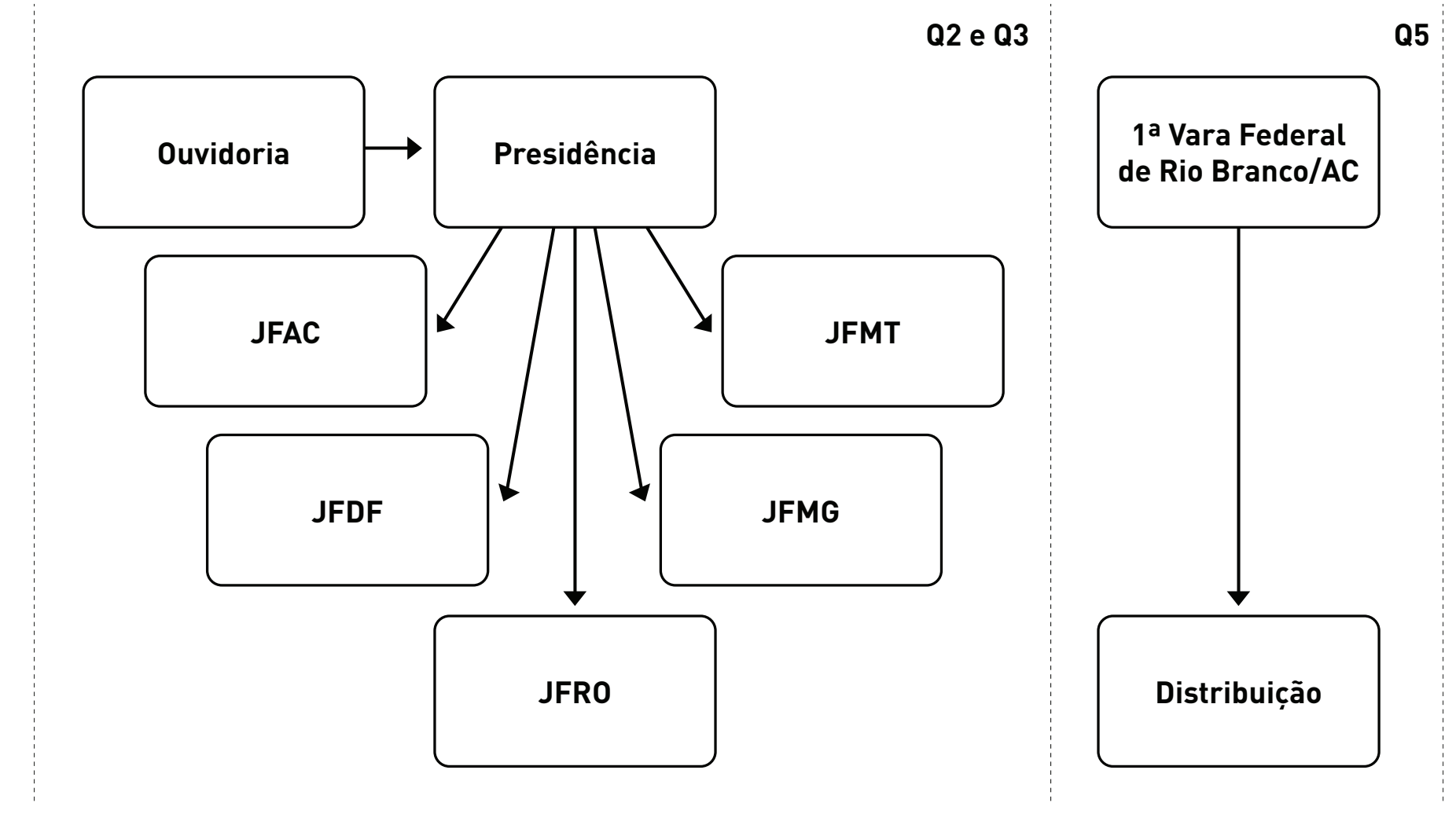

Fonte: Elaborado pelos autores.

É possível, eventualmente, atribuir essa burocracia no manejo das solicitações ao fato de o TRF1 contar com o maior número de seções judiciárias, em que pese inexistir comprovação, tampouco justificativa para esse acontecimento. A situação de redirecionamento do cidadão de um a outro setor frente a suas demandas ocasiona o oposto do que se almeja com o governo aberto, retratando a segmentação e a dificuldade em contatar as instituições públicas enquanto entes aptos a interagir de maneira responsiva às demandas sociais.

\section{CONCLUSÃO}

A pesquisa realizada apontou uma série de possibilidades, riscos e barreiras no campo do governo aberto, tendo-se realizado o esforço de trazer à tona as especificidades desses entraves no Poder Judiciário. No campo concreto, investigou-se quais são os pontos problemáticos 
que a sociedade civil encontra ao buscar dados para se informar ou produzir informação a fim de compreender as atividades e ter maior proximidade das instituições judiciais.

Isso foi feito sobretudo contrastando dados com os incrementos possibilitados pela implementação do processo eletrônico judicial. Este é visto como meio de auxílio na frente de acesso à Justiça em dois aspectos: (i) enquanto ferramenta de aproximação com o cidadão leigo; e (ii) também enquanto produtor de dados passíveis de utilização pela sociedade civil, tornando o cidadão mais familiarizado com o funcionamento processual e mais apto a participar em formulação de políticas públicas que buscam aprimorá-lo.

O estudo de caso apresentado, que foi um exercício de coleta e interpretação de registros processuais de autos findos de execuções fiscais nos cinco TRFs, teve enfoque nos entraves enfrentados. As dificuldades encontradas pela equipe de pesquisa em obter informações sobre os registros processuais podem confirmar a hipótese de que a publicidade das informações segue deficitária mesmo em um contexto de uso do processo eletrônico e da implementação da LAI.

Alguns destaques podem ser feitos quanto às principais barreiras a uma realidade concreta de governo aberto: (i) a ausência de dados abertos - o que se pôde coletar foram registros, ou seja, quadros, listas, documentos eletrônicos no formato textual não tratável por máquina, que demandariam tratamento manual antes de serem inseridos em softwares para padronização e análise informatizada; (ii) a falta de agilidade dos órgãos competentes em apresentar soluções às dúvidas da equipe de pesquisa quanto à terminologia utilizada nos registros coletados; (iii) a necessidade de acionar, em quase todos os tribunais, mais de um órgão interno a fim de remeter questionamentos acerca dos registros públicos que eles disponibilizam; (iv) o fato de que os próprios registros provêm, entre os tribunais ou até mesmo dentro de um mesmo tribunal, de materiais de natureza diferente - isto é, há processos judiciais eletrônicos, híbridos e físicos que tramitaram ou tramitam -, o que dificulta a padronização ou a fácil transposição para um banco de dados coerente que permita tratar automaticamente os dados dos registros; (v) a falta de transparência no retorno das solicitações, que foram ignoradas em alguns casos, negando esclarecimento a questões sobre a interpretação dos registros disponibilizados; (iv) a burocracia no manejo das solicitações, o que cria ainda mais obstáculos à consulta de informações e à aproximação do cidadão às instituições do Poder Judiciário, visto que o cidadão se vê diante de diretórios internos que remetem a solicitação de um para outro sem dar uma resposta institucional, unificada, a quem precisa de esclarecimento.

A escolha da instância e da matéria processual foi uma limitação imposta pelo projeto no qual este artigo se insere e pela finalidade da coleta das informações para produzir dados a serem utilizados posteriormente, de modo que se deve considerar esse recorte quanto aos resultados obtidos. É importante pontuar que os dados apresentados dizem respeito a consultas a informações de movimentações processuais de autos findos em segunda instância da Justiça Federal, podendo-se complementar a presente pesquisa em outras searas e instâncias judiciais a fim de se obter um diagnóstico mais completo da informatização processual. Casos em 
que ambas as partes do processo são cidadãos (sem instituições governamentais no litígio), ou mesmo processos cuja matéria é pública, sem grau de sigilo, podem estar mais facilmente acessíveis. Outrossim, buscas em primeira instância podem apontar para entraves de natureza diversa dos aqui relatados e que melhor retratem a realidade da maioria da informação processual e sua disponibilização.

Outro horizonte de pesquisa é o estudo das razões pelas quais esses entraves persistem, identificando-se se há questões micropolíticas e institucionais que estão sendo desconsideradas pela ampla implementação da informatização como solução para os problemas de acesso ao Poder Judiciário.

Não obstante, as barreiras encontradas para se ter acesso aos registros de ações judiciais já encerradas e que tramitaram eletronicamente, bem como a dificuldade de compreensão dos registros publicizados, demonstram que as iniciativas que permeiam o processo eletrônico passam distantes de uma proposta efetiva de governo aberto. A despeito de todo o cenário de acesso à Justiça e de maior transparência e modernização em que foi implementado, o processo eletrônico ainda não é tratado de maneira a cumprir com as promessas trazidas pela informatização.

As dificuldades, que vão desde a incompletude da transição para esse formato dentro do Poder Judiciário até a arraigada cultura de afastamento entre o funcionamento interno das instituições e o público, não se mostraram superadas no caso estudado. Isso não significa que boas práticas não estejam sendo implementadas, porém, devido aos perigos de uma estrutura incompleta de governo aberto, alguns pontos isolados de abertura acabam por ressaltar a não abertura em todos os pontos que estiverem em suas fronteiras. Essas fronteiras precisam ser expandidas e as iniciativas de abertura precisam ser predominantes, a fim de evitar o cenário de expectativas frustradas apresentado pelo processo judicial eletrônico.

\section{AGRADECIMENTOS}

Os autores agradecem ao Conselho Nacional de Desenvolvimento Científico e Tecnológico (CNPq) pelo suporte a esta pesquisa, realizada no âmbito do projeto "Ferramentas, funcionalidades e procedimentos para um processo eletrônico mais célere", em andamento, com financiamento aprovado no Processo n. 409.728/2016-0 da Chamada Universal do CNPq 2016 - Vigência: 01/06/2017$31 / 05$ /2020. Agradecem também à Coordenação de Aperfeiçoamento de Pessoal de Nível Superior (Capes) pelo suporte financeiro a bolsista de pós-doutorado integrante do projeto - Código de Financiamento 001. 


\section{REFERÊNCIAS}

ABRÃO, Carlos Henrique. Processo eletrônico: processo digital. 5. ed. Rio de Janeiro: Atlas, 2017.

ALMEIDA FILHO, José Carlos de Araújo. Processo eletrônico e teoria geral do processo eletrônico: a informatização judicial no Brasil. Rio de Janeiro: Forense, 2007.

ATHENIENSE, Alexandre. Comentários à Lei 11.419/06 e as práticas processuais por meio eletrônico nos Tribunais brasileiros. Curitiba: Juruá, 2010.

BRASIL. Constituição da República Federativa do Brasil de 1988. Brasília, DF, 5 out. 1988. Disponível em: http://www.planalto.gov.br/ccivil_03/constituicao/constituicaocompilado.htm. Acesso em: 14 maio 2018.

BRASIL. Lei n. 11.419, de 19 de dezembro de 2006. Dispõe sobre a informatização do processo judicial. Diário Oficial [da] República Federativa do Brasil. Brasília, DF, 19 dez. 2016. Disponível em: http://www. planalto.gov.br/ccivil_03/_ato2004-2006/2006/lei/111419.htm. Acesso em: 14 maio 2018.

BRASIL. Lei n. 12.527, de 18 de novembro de 2011. Regula o acesso a informações previsto no inciso XXXIII do art. $5^{\circ}$, no inciso II do $\S 3^{\circ}$ do art. 37 e no $\S 2^{\circ}$ do art. 216 da Constituição Federal; altera a Lei n. 8.112, de 11 de dezembro de 1990; revoga a Lei n. 11.111, de 5 de maio de 2005, e dispositivos da Lei n. 8.159, de 8 de janeiro de 1991; e dá outras providências. Diário Oficial [da] República Federativa do Brasil. Brasília, DF, 18 nov. 2011. Disponível em: http://www.planalto.gov.br/ccivil_03/_ato2011-2014/ 2011/lei/l12527.htm. Acesso em: 14 maio 2018.

BRASIL. Lei n. 13.105, de 16 de março de 2015. Código de Processo Civil. Diário Oficial [da] República Federativa do Brasil. Brasília, DF, 16 mar. 2015. Disponível em: http://www.planalto.gov.br/ccivil_03/ _ato2015-2018/2015/lei/113105.htm. Acesso em: 16 maio 2018.

BRASIL. Dados abertos governamentais. 2019. Disponível em: https://www.gov.br/governodigital/ptbr/dados-abertos/dados-abertos-governamentais. Acesso em: 29 jan. 2020.

BRASIL. GOVERNO FEDERAL. O que é o governo aberto. s.d. Disponível em: https: / / governoaberto. cgu.gov.br/a-ogp/o-que-e-governo-aberto. Acesso em: 5 ago. 2019.

CALDERÓN, César; LORENZO, Sebastián. Open Government: gobierno abierto. Jaén: Algón Editores, 2010.

CAPPELLETTI, Mauro; GARTH, Bryant. Acesso à Justiça. Tradução e revisão de: Ellen Gracie Northfleet. Porto Alegre: Fabris, 1988. 
CONTROLADORIA GERAL DA UNIÃO (CGU). Acesso à Informação Pública: uma introdução à Lei 12.527, de 18 de novembro de 2011. Brasília: Imprensa Nacional, 2011.

COELHO, Vera S. P.; WAISBICH, Laura T. Mecanismo independente de avaliação: relatório de progresso 2011-2013. Primeiro relatório de progresso. São Paulo: Cebrap, 2013.

CRUZ-RUBIO, César Nicandro. O que é (e o que não é) governo aberto? Uma discussão conceitual. Revista Temas de Administração Pública, v. 10, n. 1, p. 129-148, 2015.

DAHL, R. A. A democracia e seus críticos. Tradução de: Patrícia de Freitas Ribeiro. São Paulo: WMF Martins Fontes, 2012.

DALLARI, D. A. O poder dos juízes. 2. ed. rev. São Paulo: Saraiva, 2002.

DENHARDT, Robert B. Teorias da Administração Pública. Tradução da 6 a edição norte-americana e glossário de: Francisco G. Heidemann. São Paulo: Cengage Learning, 2015.

DINIZ, Vagner. Como conseguir dados governamentais abertos. In: CONGRESSO CONSAD DE GESTÃO PÚBLICA, 3, 2010. Brasília. Anais... Brasília: Consad, 2010. Disponível em: https: / /i3gov.planejamento. gov.br/como_conseguir_dados_governamentais_abertos.pdf. Acesso em: 29 jan. 2020.

GALINDO, Fernando. Gypsies, the Administration of Justice, Automation and the Resolution of Problems. In: Racial Justice, Policies and Courts' Legal Reasoning in Europe. Cham: Springer, 2017. p. 115-129.

IMPRENSA NACIONAL. Dados abertos. s.d. Disponível em: http: / /www.in.gov.br/acesso-a-informacao/ dados-abertos. Acesso em: 5 ago. 2019.

JANSSEN, Marijn; CHARALABIDIS, Yannis; ZUIDERWIJK, Anneke. Benefits, Adoption Barriers and Myths of Open Data and Open Government. Information Systems Management, v. 29, p. 258-268, 2012.

KING, Gary; KEOHANE, Robert O.; VERBA, Sidney. Designing Social Inquiry: Scientific Inference in Qualitative Research. Princeton University Press, 1994.

KURTZ, Lahis Pasquali. Tecnologias da informação e comunicação para eficiência judicial: quadro de possibilidades para a consistência das decisões. Dissertação (Mestrado) - Universidade Federal de Santa Catarina, Centro de Ciências Jurídicas, Programa de Pós-Graduação em Direito, Florianópolis, 2017.

MAIER-RABLER, Ursula; HUBER, Stefan. “Open”: The Changing Relation between Citizens, Public Administration, and Political Authority. Towards Researching the Public Value of Open Government. 
e-Journal of eDemocracy and Open Government. Krems, v. 3, n. 2, p. 182-191, 2011.

MELLO, Celso Antônio Bandeira de. Curso de Direito Administrativo. São Paulo: Editora Malheiros, 2015.

PÉREZ LUÑO, Antonio-Enrique. ¿Ciberciudadani@o ciudadania.com. Barcelona: Editorial Gedisa, 2004.

OLIVEIRA, Clarisse Inês de. O tempo morto de trabalho no processo eletrônico. In: CELLA, José Renato Gaziero; GOMES, Magno Federici; ROVER, Aires José (coord.). Direito, governança e novas tecnologias. Florianópolis: Funjab, 2015. [CONPEDI, 24. Anais...].

ORGANISATION FOR ECONOMIC CO-OPERATION AND DEVELOPMENT (OECD). Public Sector Modernisation: The Way Forward. Policy Brief. Paris: OECD, 2005.

RUVAlCABA-GOMEZ, Edgar A.; CRIADO, J. Ignacio; GIL-GARCIA; J. Ramon. Discussing Open Government as a Concept: A Comparison between the Perceptions of Public Managers and Current Academic Debate. dg.o '18, Delft, Netherlands, May 30-June 1, 2018.

SADEK, Maria Tereza Aina. Acesso à justiça: um direito e seus obstáculos. Revista USP. São Paulo, n. 101, p. 55-66, mar. /abr. / maio 2014.

SALM JÚNIOR, José F. Padrão de projeto de ontologias para inclusão de referências do novo serviço público em plataformas de governo aberto. 2012. 303 p. Tese (Doutorado) - Programa de Pós-Graduação em Engenharia e Gestão do Conhecimento, Centro Tecnológico, Universidade Federal de Santa Catarina, Florianópolis, 2012.

SANTOS, Paloma M.; BERNARDES, Marciele B.; ROVER, Aires J. Teoria e prática de governo aberto: lei de acesso à informação nos executivos municipais da região Sul. Florianópolis: Fundação Boiteux, 2012.

VAZ, José C.; RIBEIRO, Manuella M.; MATHEUS, Ricardo. Dados governamentais abertos e seus impactos sobre os conceitos e práticas de transparência no Brasil. Cadernos PPG-AU/UFBA. Salvador, Edição especial: Democracia e Interfaces Digitais para a Participação Pública, v. 9, p. 45-62, 2010.

WAMBIER, Teresa Arruda Alvim et al. Breves comentários ao Novo Código de Processo Civil. São Paulo: Editora Revista dos Tribunais, 2015. 


\section{COMO CITAR ESTE ARTIGO:}

SABO, Isabela Cristina; KURTZ, Lahis Pasquali; REGINALDO, Paula Adão; SANTOS, Paloma Maria; ROVER, Aires José. Entraves ao governo aberto na Justiça Federal brasileira. Revista Direito GV, v. 16, n. 1, jan./abr. 2020, e1950. doi: http://dx.doi.org/10.1590/ 2317-6172201950.

\section{Isabela Cristina Sabo}

Doutoranda em Direito pela Universidade Federal de Santa CATARINA (UFSC). BOLSISTA CNPQ.

isabelasabolagmail.com

\section{Lahis Pasquali Kurtz}

Doutoranda em Direito pela Universidade Federal de Minas GERAIS (UFMG).

lahiskurtzagmail.com

\section{Paula Adão Reginaldo}

Advogada. Bacharel em Direito pela Universidade Federal de Santa Catarina (UFSC).

paula7aragmail.com

Paloma Maria Santos

Pós-doutoranda em Engenharia E Gestão do Conhecimento pela Universidade Federal de Santa Catarina (UFSC).

Bolsista CAPES.

santos.palomalamail.com

Aires José Rover

Doutor em Direito pela Universidade Federal de SANTA

CATARINA (UFSC).

aires.roveragmail.com 